\title{
Modifying ICCA with Trp-Phe-Phe to Enhance in vivo Activity and Form Nano-Medicine
}

This article was published in the following Dove Press journal:

International Journal of Nanomedicine

\author{
Xiaoyi Zhang ${ }^{1,2}$ \\ Yixin Zhang ${ }^{1,2}$ \\ Yaonan Wang $\mathbb{D}^{1,2}$ \\ Jianhui $\mathrm{Wu}\left(\mathbb{D}^{1,2}\right.$ \\ Haiyan Chen ${ }^{1,2}$ \\ Ming Zhao ${ }^{1-3}$ \\ Shiqi Peng $\mathbb{D}^{1,2}$
}

'Beijing Area Major Laboratory of Peptide and Small Molecular Drugs, Department of Medicinal Chemistry, School of

Pharmaceutical Sciences, Capital Medical University, Beijing 100069, People's

Republic of China; ${ }^{2}$ Engineering Research

Center of Endogenous Prophylactic of

Ministry of Education of China,

Department of Medicinal Chemistry,

School of Pharmaceutical Sciences, Capital

Medical University, Beijing I00069, People's

Republic of China; ${ }^{3}$ Beijing Laboratory of

Biomedical Materials and Key Laboratory of

Biomedical Materials of Natural

Macromolecules, Department of

Biomaterials, College of Materials Science

and Engineering, Beijing University of

Chemical Technology, Beijing 100026,

People's Republic of China
Correspondence: Shiqi Peng; Ming Zhao Department of Medicinal Chemistry, School of Pharmaceutical Sciences,

Capital Medical University, No. 10, Youanmenwaixitoutiao, Fengtai District, Beijing 100069, People's Republic of China Tel +86 I0 839। $1528 ;+86108391 \quad 1535$ Fax +86 I0 839। I528; +86 I0 839। I533 Email sqpeng@bjmu.edu.cn; maozhao@I26.com
Background: 1-(4-isopropylphenyl)- $\beta$-carboline-3-carboxylic acid (ICCA) was modified by Trp-Phe-Phe to form 1-(4-isopropylphenyl)- $\beta$-carboline-3-carbonyl-Trp-Phe-Phe (ICCA-WFF). Purpose: The object of preparing ICCA-WFF was to enhance the in vivo efficacy of ICCA, to explore the possible targeting action, and to visualize the nano-feature.

Methods: The advantages of ICCA-WFF over ICCA were demonstrated by a series of in vivo assays, such as anti-tumor assay, anti-arterial thrombosis assay, anti-venous thrombosis assay, P-selectin expression assay, and GPIIb/IIIa expression assay. The nano-features of ICCA-WFF were visualized by TEM, SEM and AFM images. The thrombus targeting and tumor-targeting actions were evidenced by FT-MS spectrum analysis.

Results: The minimal effective dose of ICCA-WFF slowing tumor growth and inhibiting thrombosis was 10-fold lower than that of ICCA. ICCA-WFF, but not ICCA, formed nano-particles capable of safe delivery in blood circulation. In vivo ICCA-WFF, but not ICCA, can target thrombus and tumor. In thrombus and tumor, ICCA-WFF released Trp-Phe-Phe and/or ICCA.

Conclusion: Modifying ICCA with Trp-Phe-Phe successfully enhanced the anti-tumor activity, improved the anti-thrombotic action, formed nano-particles, targeted tumor tissue and thrombus, and provided an oligopeptide modification strategy for heterocyclic compounds.

Keywords: ICCA, modification, Trp-Phe-Phe, anti-tumor, thrombus targeting, release, toxicity, nano-species

\section{Introduction}

The malignant cancer is a heterogeneous disease and characterized by the different phenotypes. $^{1-3}$ Though early recognition, surgical extirpation and clinical therapy did reduce the death rate, ${ }^{4}$ the diseases, such as deep venous and arterial embolisms can induce bad outcomes of cancer patients, thereby the diseases made malignant cancer to be a response for the elevated mortality of human being of the world. ${ }^{5-9}$ In fact, the correlation between malignant cancer and thromboembolism was established for more than 150 years. Later, it was reported that the risk of hospitalized patients with cancer to develop venous thromboembolism was 4.1 times higher than that of the non-cancer patients, ${ }^{10-16}$ and conversely venous thromboembolism was one of the leading causes of the deaths of patients with some types of malignant cancer. ${ }^{17}$ In addition to venous embolism, arterial embolism was correlated with specific malignant cancer $^{18,19}$ and cancer therapies. $^{20,21}$ In this profile to discover lead compounds capable of simultaneously inhibiting arterial thrombosis, preventing venous thrombosis and slowing tumor growth is of great clinical importance. As an effort, 1-(4-isopropylphenyl)- $\beta$ carboline-3-carboxylic acid (ICCA) was recently reported as an agent capable of 
simultaneously inhibiting GPIIb/IIIa, P-selectin, arterial thrombosis, venous thrombosis and tumor growth. ${ }^{22}$ However, its oral dose $(5 \mu \mathrm{mol} / \mathrm{kg})$ was a bit high. To lower the dose, some oligopeptides were previously designed, prepared and evaluated for modifying ICCA. Among them, TrpPhe-Phe was found having anti-tumor and anti-thrombotic activities, as well as depressing serum P-selectin and GPIIb/ IIIa in particular. This led to a hypothesis that coupling ICCA with Trp-Phe-Phe should form the derivative capable of binding GPIIb/IIIa and P-selectin. In this case, 1-(4-iso propylphenyl)- $\beta$-carboline-3-carbonyl-Tyr-Phe-Phe (ICCAWFF) was designed and docked into the active sites of P-selectin and GPIIb/IIIa.

\section{Materials and Methods}

\section{General}

Trp and Phe purchased from Sigma were $L$-configuration. All reactions were done in nitrogen (1 bar). On Bruker AMX-300 and $\mathrm{AMX}-800$ spectrometer ${ }^{1} \mathrm{H}(300$ and $800 \mathrm{MHz})$ and ${ }^{13} \mathrm{C}$ (75 and $200 \mathrm{MHz}$ ) NMR spectra were measured for the intermediates or ICCA-WFF, for which dimethylsulfoxide (DMSO- $d_{6}$ ) was the solvent and tetramethylsilane was the internal standard. Perkin-Elmer 983 instrument was used to record IR spectra. ESI( \pm )-ICR-FT-MS spectrum was recorded on a 9.4 T solariX Fourier transform ion cyclotron resonance mass spectrometer (Bruker Corp, Billerica, MA, USA) to get the exact mass of ICCA-WFF. Chromatography was performed by using Sephadex- $\mathrm{LH}_{20}$ or Qingdao silica gel $\mathrm{GF}_{254}$ or Qingdao silica gel $\mathrm{H}_{60}$. All solvents were distilled and dried by the literature procedures for use. HPLC purity (Waters, $\mathrm{C}_{18}$ column $4.6 \times 150 \mathrm{~mm}$ ) of the intermediates and ICCA-WFF were more than $96 \%$ and $99.63 \%$, respectively. HPLC was performed with Agilent Technologies 1200 Series HPLC system (Agilent Technologies, Santa Clara, CA, USA) on Eclipse XDB C18 column $(5 \mu \mathrm{m}, 4.6 \mathrm{~mm} \times 150 \mathrm{~mm})$. The column temperature was $40^{\circ} \mathrm{C}$, the mobile phase consisted of water and methanol, and the gradient consisted of $60 \%$ methanol (0-5 min), 70\% methanol (5-10 min), 80\% methanol (10-20 $\mathrm{min}$ ) and 90\% methanol (20-30 min), while the flow rate was $0.8 \mathrm{~mL} / \mathrm{min}$. Ultraviolet (UV) absorption spectrum was recorded online. The UV detector was set to a scanning range of 200-400 $\mathrm{nm}$, and the chromatogram of ICCA-WFF was monitored at a wavelength of $280 \mathrm{~nm}$.

\section{Animals and Cell Lines}

Human myeloid leukemia cells (K562), human non-small cell lung cancer cells (A549), non-small cell lung cancer cells (95D) and ascites tumor cells (S180) were purchased from keyGEN BioTECH (Nanjing China).

From the Laboratory Animal Center of Capital Medical University male ICR mice (22-24 g) and male Sprague Dawley rats (240-270 g) were purchased. Ethics Committee of Capital Medical University reviewed and approved the protocol of the evaluations. In particular, the animal welfare fulfilled the requirements of the Animal Welfare Act and NIH Guide for Care and Use of Laboratory Animals.

Biological data were statistically analyzed with ANOVA. LSD for multiple group comparison. SPSS 19.0-program was used to perform the analysis and a P-value less than 0.05 was considered statistically significant.

\section{Synthesis}

The preparations and the physical-chemical data of (1R,3S)1-(4-isopropylphenyl)-2,3,4,9-tetrahydro- $\beta$-carboline-3-carboxylic acid benzyl esters(1), benzyl 1-(4-isopropylphenyl)$\beta$-carboline-3-carboxylate (2) and ICCA were the same as those of the literature. ${ }^{22}$

\section{Preparation of Boc-Phe-Phe-OBzl}

At $0^{\circ} \mathrm{C}$ to a solution of $13.00 \mathrm{~g}(49.02 \mathrm{mmol})$ of Boc-Phe in $200 \mathrm{~mL}$ of anhydrous THF $6.02 \mathrm{~g}(44.59 \mathrm{mmol})$ of HOBt and $11.00 \mathrm{~g}$ (53.39 mmol) of DCC were added. This solution was at $0^{\circ} \mathrm{C}$ stirred for $30 \mathrm{~min}$ and as solution $\mathrm{A}$ for the coming use. A solution of $13.00 \mathrm{~g}(44.56 \mathrm{mmol})$ of $\mathrm{HCl} \cdot \mathrm{Phe}-\mathrm{OBzl}$ in $100 \mathrm{~mL}$ of anhydrous THF was adjusted to $\mathrm{pH} 9$ with NMM. This solution was firstly combined with solution A to form a reaction mixture and then stirred at room temperature, of which $\mathrm{pH} 9$ was maintained by adding NMM. Six hours after the stirring TLC (petroleum/acetone,2/1) indicated the complete disappearance of $\mathrm{HCl} \cdot \mathrm{Phe}-$ OBzl. The reaction mixture was filtered, the filtrate was evaporated in vacuum and the residue was dissolved in $150 \mathrm{~mL}$ of ethyl acetate. This solution was successively washed with saturated aqueous $\mathrm{NaHCO}_{3}(50 \mathrm{~mL} \times 3), 5 \%$ aqueous $\mathrm{KHSO}_{4}(50 \mathrm{~mL} \times 3)$, saturated aqueous $\mathrm{NaCl}$ $(50 \mathrm{~mL} \times 3)$, saturated aqueous $\mathrm{NaHCO}_{3}(50 \mathrm{~mL} \times 3)$ and saturated aqueous $\mathrm{NaCl}(50 \mathrm{~mL} \times 3)$. Ethyl acetate phase was isolated, dried with anhydrous $\mathrm{Na}_{2} \mathrm{SO}_{4}$ for $12 \mathrm{hrs}$, filtered, the filtrate was evaporated in vacuum and the residue was purified on silica gel column (petroleum/acetone,5/1) to give $20.2 \mathrm{~g}(90 \%)$ of title compound as colorless powders. ${ }^{1} \mathrm{H}$ NMR $(300 \mathrm{MHz}, \mathrm{DMSO}-d 6): \delta / \mathrm{ppm}=8.45(\mathrm{~d}$, $J=7.2 \mathrm{~Hz}, 1 \mathrm{H}), 7.24(\mathrm{~m}, 15 \mathrm{H}), 6.88$ (d, $J=8.7 \mathrm{~Hz}, 1 \mathrm{H})$, $5.07(\mathrm{~m}, 2 \mathrm{H}), 4.56(\mathrm{~m}, 1 \mathrm{H}), 4.20(\mathrm{~m}, 1 \mathrm{H}), 3.04(\mathrm{~m}, 2 \mathrm{H})$, 
$2.87(\mathrm{~m}, 1 \mathrm{H}), 2.60(\mathrm{~m}, 1 \mathrm{H}), 1.30(\mathrm{~s}, 9 \mathrm{H}) . \mathrm{ESI}(+)-\mathrm{MS}(\mathrm{m} / \mathrm{z})$ : $503[\mathrm{M}+\mathrm{H}]^{+}$.

\section{Preparation of Phe-Phe-OBzl}

At $0^{\circ} \mathrm{C}$ to a solution of $10.0 \mathrm{~g}(19.9 \mathrm{mmol})$ of Boc-Phe-PheOBzl in $50 \mathrm{~mL}$ of anhydrous ethyl acetate, a solution of hydrogen chloride in anhydrous ethyl acetate $(50 \mathrm{~mL}, 4 \mathrm{M})$ was added. Four hours after stirring TLC (petroleum ether/ acetone, 2/1) indicated the complete disappearance of BocPhe-Phe-OBzl. This reaction mixture was evaporated in vacuum and the residue was dissolved in $50 \mathrm{~mL}$ of anhydrous ethyl acetate for evaporation. This procedure was repeated for at least 3 times to remove the access hydrogen chloride thoroughly, which provided $7.72 \mathrm{~g}(96.5 \%)$ of the title compound as colorless powders. $\mathrm{ESI}(+)-\mathrm{MS}(\mathrm{m} / \mathrm{z}): 403[\mathrm{M}+\mathrm{H}]^{+}$.

\section{Preparation of Boc-Trp-Phe-Phe-OBzl}

By using the procedure of item 2 from $12.39 \mathrm{~g}$ (40.7 mmol) of Boc-Trp and $14.95 \mathrm{~g}(37.02 \mathrm{mmol})$ of Phe-PheOBzl $10.02 \mathrm{~g} \mathrm{(40 \% )} \mathrm{of} \mathrm{the} \mathrm{title} \mathrm{compound} \mathrm{was} \mathrm{obtained} \mathrm{as}$ colorless powders. ${ }^{1} \mathrm{H}$ NMR (300 MHz, DMSO-d6): $\delta /$ $\mathrm{ppm}=10.76(\mathrm{~s}, 1 \mathrm{H}), 8.62(\mathrm{~d}, J=7.5 \mathrm{~Hz}, 1 \mathrm{H}), 7.90(\mathrm{~d}$, $J=8.4 \mathrm{~Hz}, 1 \mathrm{H}), 7.52(\mathrm{~d}, J=7.8 \mathrm{~Hz}, 1 \mathrm{H}), 7.27$ (m, 16H), $7.02(\mathrm{~m}, 3 \mathrm{H}), 6.75(\mathrm{~d}, J=8.4 \mathrm{~Hz}, 1 \mathrm{H}), 5.07$ (m, 2H), 4.64 $(\mathrm{m}, 2 \mathrm{H}), 4.57(\mathrm{q}, J=7.2 \mathrm{~Hz}, 1 \mathrm{H}), 4.14(\mathrm{~m}, 1 \mathrm{H}), 2.90(\mathrm{~m}$, 6H), 1.27 (s, 9H). ESI(+)-MS (m/z): $689[\mathrm{M}+\mathrm{H}]^{+}$.

\section{Preparation of Trp-Phe-Phe-OBzl}

By using the procedure of item 3 from $5.0 \mathrm{~g}(7.3 \mathrm{mmol})$ of Boc-Trp-Phe-Phe-OBzl $4.06 \mathrm{~g}(95 \%)$ of the title compound was obtained as colorless powders. ESI(+)-MS $(\mathrm{m} / \mathrm{z}): 589[\mathrm{M}+\mathrm{H}]^{+}$.

\section{Preparation of Trp-Phe-Phe}

Into a suspension of $1.60 \mathrm{~g}$ (2.7 mmol) of Trp-Phe-Phe-OBzl and $160 \mathrm{mg}$ of $\mathrm{Pd} / \mathrm{C}$ in $30 \mathrm{~mL}$ of $\mathrm{CH}_{2} \mathrm{Cl}_{2}$ hydrogen was introduced for $10 \mathrm{hrs}$, and TLC $\left(\mathrm{CH}_{2} \mathrm{Cl}_{2} / \mathrm{CH}_{3} \mathrm{OH}, 10 / 1\right)$ indicated the complete disappearance of Trp-Phe-Phe-OBzl. The reaction mixture was filtered, the filtrate was evaporated under vacuum and the residue was grinded in anhydrous ether to give $720 \mathrm{mg}(53 \%)$ of the title compound as the colorless powders. $\mathrm{Mp} 187-189^{\circ} \mathrm{C} ;[\alpha]^{25} \mathrm{D}=-72.4(\mathrm{c}=0.106$, $\mathrm{CH}_{3} \mathrm{OH}$ ); IR (KBr): 3290, 3060, 3029, 2926, 2853, 1656 , 1639, 1519, 1495, 1454, 1435, 739, 697, $\mathrm{cm}^{-1 ; 1} \mathrm{H}$ NMR (300 MHz, DMSO-d6): $\delta / \mathrm{ppm}=10.91(\mathrm{~s}, 1 \mathrm{H}), 8.33(\mathrm{~d}, J=7.5$ $\mathrm{Hz}, 1 \mathrm{H}), 8.25$ (d, $J=7.2 \mathrm{~Hz}, 1 \mathrm{H}), 7.59$ (d, $J=7.5 \mathrm{~Hz}, 1 \mathrm{H})$, $7.34(\mathrm{~d}, J=7.8 \mathrm{~Hz}, 1 \mathrm{H}), 7.16(\mathrm{~m}, 14 \mathrm{H}), 6.97$ (t, $J=7.5 \mathrm{~Hz}$, 1H), 4.57 (m, 1H), 4.37 (m, 1H), 3.57 (m, 1H), 3.17 (s, 1H), $3.1(\mathrm{~m}, 1 \mathrm{H}), 2.99(\mathrm{~m}, 3 \mathrm{H}), 2.76(\mathrm{~m}, 2 \mathrm{H}) ;{ }^{13} \mathrm{C} \mathrm{NMR}(75 \mathrm{MHz}$,
DMSO-d6): $\delta / \mathrm{ppm}=173.24,172.78,170.88,138.38,137.83$, $136.78,129.84,129.71,128.51,128.39,127.79,126.67$, $124.68,121.42,118.94,118.75,111.84,109.85,54.84$, 54.47, 53.73, 38.18, 37.38, 30.04; HPLC purity: 99.17\%; ESI(-)-ICR-FT-MS: 497.2179 [M-H] ${ }^{-}$(calculated value: 497.2188).

\section{Preparation of I-(4-isopropylphenyl)- $\beta$ - carboline-3-carbonyl-Tyr-Phe-Phe-OBzl (3)}

By using the procedure of item 2 from $2.75 \mathrm{~g}(8.3 \mathrm{mmol})$ of ICCA and $5.89 \mathrm{~g}(10.0 \mathrm{mmol})$ of Trp-Phe-Phe-OBzl 5.1 $\mathrm{g}(68 \%)$ of title compound was obtained as colorless powders. IR (KBr): 3396, 3295, 3064, 3029, 2960, 2921, 2862, $1725,1651,1523,1495,1454,1392,1356,1212,1173$, 1100, 739, 698 $\mathrm{cm}^{-1 .}{ }^{1} \mathrm{H}$ NMR (300 MHz, DMSO-d6): $\delta /$ $\mathrm{ppm}=11.82(\mathrm{~s}, 1 \mathrm{H}), 10.84(\mathrm{~s}, 1 \mathrm{H}), 8.74(\mathrm{~s}, 1 \mathrm{H}), 8.60(\mathrm{~s}$, $1 \mathrm{H}), 8.58$ (s, 1H), 8.35 (d, $J=9 \mathrm{~Hz}, 1 \mathrm{H}), 8.30$ (d, $J=9 \mathrm{~Hz}$, 1H), 7.85 (s, 1H), 7.83 (s, 1H), 7.67 (d, J=9 Hz, 1H), 7.59 $(\mathrm{d}, J=7.8 \mathrm{~Hz}, 2 \mathrm{H}), 7.53(\mathrm{~s}, 1 \mathrm{H}), 7.50(\mathrm{~s}, 1 \mathrm{H}), 7.17(\mathrm{~m}$, $19 \mathrm{H}), 6.85(\mathrm{t}, J=6 \mathrm{~Hz}, 1 \mathrm{H}), 5.06(\mathrm{t}, J=12 \mathrm{~Hz}, 2 \mathrm{H}), 4.64(\mathrm{q}$, $J=6.6 \mathrm{~Hz}, 1 \mathrm{H}), 4.66(\mathrm{~m}, 2 \mathrm{H}), 3.18(\mathrm{~m}, 2 \mathrm{H}), 3.0(\mathrm{~m}, 4 \mathrm{H})$, $2.79(\mathrm{~m}, 1 \mathrm{H}), 1.34$ (d, $J=6.6 \mathrm{~Hz}, 6 \mathrm{H}) .{ }^{13} \mathrm{C} \mathrm{NMR}(75 \mathrm{MHz}$, DMSO-d6): $\delta / \mathrm{ppm}=172.07,171.58,164.72,149.79$, 142.02 , 141.12, 139.55, 137.36, 136.60, 136.45, 136.15, $135.50,134.64,130.14,129.55,128.93,128.79,128.73$, $128.44,128.33,128.02,127.84,127.32,126.99,124.36$, $123.93,122.36,121.65,121.23,120.63,119.02,118.82$, $118.62,113.16,111.71,110.44,110.10,66.45,54.36$, $53.83,53.60,38.71,37.23,33.90,28.59,28.25,24.36$, 24.30. $\operatorname{ESI}(+)-\mathrm{MS}(\mathrm{m} / \mathrm{z}): 901[\mathrm{M}+\mathrm{H}]^{+}$.

\section{Preparation of I-(4-isopropylphenyl)- $\beta$ -} carboline-3-carbonyl-Tyr-Phe-Phe (ICCA-WFF)

By using the procedure of item 6 from $1.0 \mathrm{~g}$ (1.2 $\mathrm{mmol})$ of 1 -(4-isopropylphenyl)- $\beta$-carboline-3-carbonyl-Tyr-Phe-Phe-OBzl (3) $802 \mathrm{mg}$ (89\%) of the title compound was obtained as powders with light pink color. Mp 170-172 ${ }^{\circ} \mathrm{C}$; $[\alpha]^{25}=-53.27$ (c=0.106, $\mathrm{CH}_{3}$ $\mathrm{OH})$; IR (KBr): 3297, 3029, 2963, 1731, 1650, 1625, 1558, 1511, 1492, 1454, 1349, 841, 737, $698 \mathrm{~cm}^{-1}$; ${ }^{1} \mathrm{H}$ NMR (800 MHz, DMSO-d6): $\delta / \mathrm{ppm}=12.74(\mathrm{~s}$, $1 \mathrm{H}), 11.82(\mathrm{~s}, 1 \mathrm{H}), 10.84(\mathrm{~s}, 1 \mathrm{H}), 8.74(\mathrm{~s}, 1 \mathrm{H}), 8.58(\mathrm{~d}$, $J=8.0 \mathrm{~Hz}, 1 \mathrm{H}), 8.36(\mathrm{~m}, 2 \mathrm{H}), 8.26(\mathrm{~d}, J=8.0 \mathrm{~Hz}$, 1H), 7.84 (d, $J=8.0 \mathrm{~Hz}, 2 \mathrm{H}), 7.67$ (d, $J=8.0 \mathrm{~Hz}, 1 \mathrm{H})$, $7.58(\mathrm{dd}, J=8.8 \mathrm{~Hz}, 7.2 \mathrm{~Hz}, 2 \mathrm{H}), 7.51$ (d, $J=8.0 \mathrm{~Hz}$, 2H), $7.30(\mathrm{dd}, J=17.6 \mathrm{~Hz}, 8.8 \mathrm{~Hz}, 2 \mathrm{H}), 7.25$ (m, 4H), $7.19(\mathrm{~d}, J=7.2 \mathrm{~Hz}, 2 \mathrm{H}), 7.16(\mathrm{~m}, 1 \mathrm{H}), 7.15(\mathrm{~m}, 1 \mathrm{H})$, $7.11(\mathrm{t}, J=8.0 \mathrm{~Hz}, 2 \mathrm{H}), 7.04(\mathrm{t}, J=7.2 \mathrm{~Hz}, 1 \mathrm{H}), 7.01$ $(\mathrm{t}, J=8.0 \mathrm{~Hz}, 1 \mathrm{H}), 6.84(\mathrm{t}, J=8.0 \mathrm{~Hz}, 1 \mathrm{H}), 4.81$ 
$(\mathrm{q}, J=7.2 \mathrm{~Hz}, 1 \mathrm{H}), 4.64(\mathrm{~m}, 1 \mathrm{H}), 4.47(\mathrm{q}, J=6.4 \mathrm{~Hz}$, 1H), 3.38 (dd, $J=14.4 \mathrm{~Hz}, 7.2 \mathrm{~Hz}, 1 \mathrm{H}), 3.18(\mathrm{~m}, 2 \mathrm{H})$, $3.05(\mathrm{~m}, 3 \mathrm{H}), 2.96(\mathrm{~m}, 1 \mathrm{H}), 2.81(\mathrm{~m}, 1 \mathrm{H}), 1.33(\mathrm{~s}$, $6 \mathrm{H}) .{ }^{13} \mathrm{C} \quad \mathrm{NMR} \quad(200 \mathrm{MHz}, \quad$ DMSO-d6): $\delta / \mathrm{ppm}$ $=173.14,171.45,171.41,164.72,149.81,142.01$, $141.13, \quad 139.49, \quad 138.01, \quad 137.82, \quad 136.58,135.48$, $134.64,130.13,129.71,129.57,129.02,128.93$, $128.68,128.35,128.01,127.33,126.90,126.58$, $124.31,122.41,121.65,121.30,120.66,118.98$, $118.71,113.20,111.72,110.06,54.04,53.96,53.74$, $38.00,37.26,33.91,28.38,24.37,24.31$. HPLC purity: 99.63\%;ESI(-)-ICR-FT-MS (m/z): $809.3448 \quad[\mathrm{M}-\mathrm{H}]^{-}$ (calculated value, 809.3451).

\section{FT-ICR-MS and qCID Spectra}

To reveal ICCA-WFF's molecule assembly its FT-ICR-MS and qCID spectra were measured on Bruker 9.4 T solariX FT-ICR mass spectrometer. The measurement was performed by following the procedure of the equipment.

\section{NOESY 2D 'H NMR Spectrum}

To reveal the manner of ICCA-WFF's molecule assembly its NOESY 2D NMR spectrum was measured on Bruker $800 \mathrm{MHz}$ spectrometer. The measurement was performed by following the procedure of the equipment.

\section{SEM, TEM and AFM Feature}

To visualize the nano-feature of ICCA-WFF in lyophilized powders, in water and in rat plasma its scanning electron microscopy (SEM) image, transmission electron microscopy (TEM) image and atomic force microscopy (AFM) image were recorded by following the procedure. In addition, the nano-property of aqueous ICCA-WFF was identified by Faraday-Tyndall effect. ${ }^{22}$

\section{Mesoscale Simulation of Nano-Particle}

The structure and conformation of ICCA-WFF were generated with ChemDraw Ultra 10.0 (Cambridge Soft) and Materials Studio 3.2 (Accelrys, Inc. USA), and then the conformation optimization, the molecular dynamic simulation, the equilibration of the structure, the building of a rigid coarse grain model of 4 connected spherical beads, and the simulation of 15,000 ps was performed by following the method. ${ }^{21}$

\section{Bioassays}

In vitro Anti-Proliferation Assay

The in vitro viability assays of human myeloid leukemia cells (K562), ascites tumor cells (S180), human non-small cell lung cancer cells (A549) and non-small cell lung cancer cells (95D) were performed by using the method of 3-(4,5-dimethylthiazol-2-yl)-2,5-diphenyltetrazolium bromide (MTT). ${ }^{23}$

\section{In vivo Anti-Tumor Assay}

On S180 mouse model this assay was carried out, and the mice were divided into 7 groups (each 12). ${ }^{24}$ The mice in positive control group were intraperitoneally injected doxorubicin (Dox, $2 \mu \mathrm{mol} / \mathrm{kg} / \mathrm{day}$ ) for 9 consecutive days, the mice in negative control group were orally given $\mathrm{CMCNa}$ (carboxymethyl cellulose sodium, $0.5 \%$ ) for 9 consecutive days, the mice in parent compound control group were orally given ICCA $(5 \mu \mathrm{mol} / \mathrm{kg} / \mathrm{day})$ for 9 consecutive days, the mice in modification control group were orally given Trp-Phe-Phe (5 $\mu \mathrm{mol} / \mathrm{kg} /$ day) for 9 consecutive days, the mice in object compound group were orally given ICCA-WFF $(5,0.5$ and $0.05 \mu \mathrm{mol} / \mathrm{kg} /$ day) for 9 consecutive days.

\section{Testing Serum ALT, AST and $\mathrm{Cr}$}

The serum was prepared by centrifuging $(1000 \mathrm{~g}, 10 \mathrm{~min})$ blood $(0.5 \mathrm{~mL})$ of $\mathrm{S} 180$ mice treated by CMCNa or ICCAWFF $(5 \mu \mathrm{mol} / \mathrm{kg} /$ day $)$. Serum glutamic pyruvictran-saminase (ALT), glutamic oxaloacetictransaminase (AST) and creatinine $(\mathrm{Cr})$ were tested by using the procedure of literature and ALT/GPT Assay Kit (Nanjing Jiancheng Bioengineering Institute, PR China). ${ }^{25}$

\section{Testing Serum BUN}

The serum was prepared by centrifuging ( $3000 \mathrm{~g}, 10 \mathrm{~min})$ the blood $(0.5 \mathrm{~mL})$ of $\mathrm{S} 180$ mice treated by CMCNa or ICCAWFF $(5 \mu \mathrm{mol} / \mathrm{kg} /$ day). Blood urea nitrogen (BUN) was tested by using the procedure of literature and the procedure of the kit (Shanghai Lianshuo Biological Technology Co., Ltd, PR China). ${ }^{25}$

\section{Arterial Thrombus Weight Assays}

Arterial thrombus weight assay was performed on male ICR mouse (22-24 g, each 12) model or on male Sprague Dawley rat (240-270 g, each 12) model by following the procedure of the literature. ${ }^{25,26}$ In mouse arterial thrombus weight assay $0.5 \% \mathrm{CMCNa}(10 \mathrm{~mL} / \mathrm{kg}$, negative control) or a suspension of aspirin in $0.5 \% \mathrm{CMCNa}(240 \mu \mathrm{mol} / \mathrm{kg}$, positive control $)$ or a suspension of ICCA in $0.5 \% \mathrm{CMCNa}(5 \mu \mathrm{mol} / \mathrm{kg})$ or a suspension of WFF in $0.5 \% \mathrm{CMCNa}(5 \mu \mathrm{mol} / \mathrm{kg})$ or a suspension of ICCA-WFF in $0.5 \% \mathrm{CMCNa}(5,0.5$ and $0.05 \mu \mathrm{mol} / \mathrm{kg}$ ) were orally given. In rat arterial thrombus weight assay $0.5 \% \mathrm{CMCNa}(3 \mathrm{~mL} / \mathrm{kg})$ or suspension of aspirin in $0.5 \% \mathrm{CMCNa}(167 \mu \mathrm{mol} / \mathrm{kg})$ or a suspension of 
ICCA in $0.5 \% \mathrm{CMCNa}(5 \mu \mathrm{mol} / \mathrm{kg})$ or a suspension of WFF in $0.5 \% \mathrm{CMCNa}(5 \mu \mathrm{mol} / \mathrm{kg})$ or a suspension of ICCA-WFF in $0.5 \% \mathrm{CMCNa}(5,0.5$ and $0.05 \mu \mathrm{mol} / \mathrm{kg})$ were orally given.

\section{P-selectin and GPIlb/llla Expression Assays}

The level of P-selectin expression was identified with an enzyme-linked immune-sorbent assay (ELISA). The procedure of the literature and the kit (rat P-selectin ELISA kit; Wuhan Huamei Biotech Co., Ltd., Wuhan, Hubei Province, PR China) was used. ${ }^{26}$ GPIIb/IIIa expression was similarly identified with ELISA. The procedure of the literature and the kit (rat GPIIb/IIIa ELISA kit; Wuhan Huamei Biotech Co., Ltd., Wuhan, Hubei Province, PR China) was used. ${ }^{27}$ In ELISA the serum was prepared from the blood of the rats treated by ICCA $(5 \mu \mathrm{mol} / \mathrm{kg})$ or by aspirin $(167 \mu \mathrm{mol} / \mathrm{kg}$, positive control) or by ICCA-WFF $(5,0.5$ and $0.05 \mu \mathrm{mol} / \mathrm{kg})$ or by $0.5 \% \mathrm{CMCNa}(3 \mathrm{~mL} / \mathrm{kg}$, negative control).

\section{Rat Tail Bleeding Time Assay}

This assay was performed by following the procedure of the literature. ${ }^{28}$ In assay the male Sprague Dawley rats (240-270 g, each 12$)$ were orally treated with $0.5 \% \mathrm{CMCNa}(3 \mathrm{~mL} / \mathrm{kg}$, negative control) or a suspension of aspirin in $0.5 \% \mathrm{CMCNa}$ (167 $\mu \mathrm{mol} / \mathrm{kg}$, positive control) or a suspension of ICCA in $0.5 \% \mathrm{CMCNa}(5 \mu \mathrm{mol} / \mathrm{kg})$ or a suspension of ICCA-WFF in $0.5 \% \mathrm{CMCNa}(5,0.5$ and $0.05 \mu \mathrm{mol} / \mathrm{kg})$.

\section{Venous Thrombus Weight Assay}

This assay was performed by following the procedure of the literature. ${ }^{26}$ In assay male Sprague Dawley rats (240-270 g, each 12$)$ were orally treated with $0.5 \% \mathrm{CMCNa}(3 \mathrm{~mL} / \mathrm{kg}$, negative control) or warfarin in $0.5 \% \mathrm{CMCNa}(4.87 \mu \mathrm{mol} /$ $\mathrm{kg}$, positive control) or ICCA in $0.5 \% \mathrm{CMCNa}(5 \mu \mathrm{mol} / \mathrm{kg})$ or ICCA-WFF in $0.5 \% \mathrm{CMCNa}(5,0.5$ and $0.05 \mu \mathrm{mol} / \mathrm{kg})$.

\section{Testing PT, TT, APTT and FIB}

To estimate the effect of ICCA-WFF on the prothrombin time (PT), thrombin time (TT), activated partial thromboplastin time (APTT) and plasma fibrinogen (FIB) the blood of $0.5 \%$ $\mathrm{CMCNa}(3 \mathrm{~mL} / \mathrm{kg}$, negative control, 12 rats) or ICCA-WFF in $0.5 \% \mathrm{CMCNa}(5 \mu \mathrm{mol} / \mathrm{kg}, 12$ rats) treated rats in the venous thrombosis assay was used to prepare the serum. Then, PT, TT, APTT and FIB were recorded on the semi-automatic blood coagulation instrument (Virtues Pacific Biological Polytron Technologies Inc., Tianjin, People's Republic of China). ${ }^{22}$

\section{Docking Toward the Active Sites of P-selectin and GPIIb/IIla}

To show the superiority of ICCA-WFF to ICCA in fitting the active site of both P-selectin and GPIIb/IIIa the CDOCKER interaction energies were calculated. For this purpose, the conformations of ICCA-WFF and ICCA were generated, and 10 energy optimized conformations of ICCA-WFF and ICCA were docked into the active sites of P-selectin and GPIIb/IIIa with CDOCKER protocol and using the procedure of the literature. ${ }^{26,30}$

\section{Molecular Assembly and Thrombus Targeting Action FT-ICR-MS and Corresponding Characterization}

Molecular assembly of ICCA-WFF was identified with FTICR-MS spectra, while the manner of the molecular assembly was identified with the nuclear over hauser effect spectroscopy (NOESY) and energy optimization conformation. These methods were in accordance with the literature. ${ }^{31}$

\section{FT-ICR-MS Analysis of Homogenate Extracts}

To explore the targeting action the blood, brain, heart, kidney, liver, spleen and thrombus of arterial thrombosis rats treated with $0.5 \% \mathrm{CMCNa}(3 \mathrm{~mL} / \mathrm{kg}$, negative control, 12 rats) or ICCA-WFF in $0.5 \% \mathrm{CMCNa}(5 \mu \mathrm{mol} / \mathrm{kg}, 12$ rats) were homogenized, the homogenates were extracted with methanol and the extracts received FT-ICR-MS tests. Besides, the tumor tissue, blood, brain, heart, kidney, liver and spleen of S180 mice treated with $0.5 \% \mathrm{CMCNa}$ (3 $\mathrm{mL} / \mathrm{kg}$, negative control, 12 rats) or a suspension of ICCA-WFF in $0.5 \% \mathrm{CMCNa}(5 \mu \mathrm{mol} / \mathrm{kg}, 12$ rats $)$ were homogenized, the homogenates were extracted with methanol and the extracts received FT-ICR-MS analysis. These methods were in accordance with literature. ${ }^{22,29,31}$

\section{Confocal Microscope Imaging}

To show the cellular uptake of ICCA-WFF the confocal microscope image was visualized. At $37^{\circ} \mathrm{C} 95 \mathrm{D}$ cells $\left(1 \times 10^{5}\right.$ cells $\left./ \mathrm{mL}\right)$ were incubated in complete RPMI 1640 medium containing $10 \%(\mathrm{v} / \mathrm{v})$ fetal calf serum, penicillin $(60 \mu \mathrm{g} / \mathrm{mL})$, and streptomycin $(100 \mu \mathrm{g} / \mathrm{mL})$, as well as $\mathrm{CO}_{2}$ (a humidified atmosphere, 5\%) for $24 \mathrm{hrs}$. After removing the original medium, the complete RPMI 1640 medium or a solution of ICCA-WFF in the complete RPMI 1640 medium (final concentration: $55 \mu \mathrm{M}, 27.5$ $\mu \mathrm{M}$ and $13.5 \mu \mathrm{M})$ was added ( $1 \mathrm{~mL} /$ well $)$, and the cells were incubated for another $12 \mathrm{~h}$. After removing the medium, the cells were washed with fresh medium 
$(1 \mathrm{~mL} \times 3)$ and resuspended in fresh medium $(1 \mathrm{~mL} /$ well $)$. The cells treated by the complete RPMI 1640 medium or a solution of ICCA-WFF in the complete RPMI 1640 medium were analyzed by the use of TCS SP8 STED confocal microscopy (Leica, Leica Microsystems, Wetzlar, Germany). The excitation wavelength and the emission wavelength were $405 \mathrm{~nm}$ and $575 \mathrm{~nm}$, respectively.

\section{Results}

\section{Trp-Phe-Phe Was Found to Be Suitable for Modifying ICCA}

To lower the dose of ICCA some oligopeptides were previously designed, prepared and evaluated. Among them TrpPhe-Phe was found to be capable of slowing tumor growth, inhibiting thrombosis, and depressing serum P-selectin and GPIIb/IIIa in particular (Figure 1).

Thus, a derivative of ICCA coupling Trp-Phe-Phe could bind GPIIb/IIIa and P-selectin was hypothesized, and a docking investigation was performed. Figure 2 shows that the CDOCKER interaction energies of ICCA and ICCA-WFF with P-selectin are $-20.5 \mathrm{kcal} / \mathrm{mol}$ and $-40.3 \mathrm{kcal} / \mathrm{mol}$, respectively. Figure 2 also shows that the CDOCKER interaction energies of ICCA and ICCA-WFF with GPIIb/IIIa are $-23.9 \mathrm{kcal} / \mathrm{mol}$ and $-41.6 \mathrm{kcal} / \mathrm{mol}$, respectively. For P-selectin and GPIIb/IIIa, the CDOCKER interaction energies of ICCA-WFF are significantly lower than those of ICCA.

The multiple activities of Trp-Phe-Phe in vivo with the CDOCKER interaction energy of ICCA-WFF to be lower than that of ICCA together suggested that Trp-Phe-Phe was suitable for modifying ICCA.

\section{The Route Is Suitable to the Preparation of ICCA-WFF}

To process the forward investigations, ICCA-WFF was synthesized by following the route of Figure 3 . This route consists of the synthesis of ICCA, the preparation of Trp-PhePhe-OBzl and the coupling of ICCA with Trp-Phe-Phe-OBzl. It was found that the overall yields of the synthesis of ICCA, the preparation of Trp-Phe-Phe-OBzl and the coupling of ICCA with Trp-Phe-Phe-OBzl were $73 \%, 83 \%$ and $61 \%$, respectively, while the HPLC purity of ICCA-WFF was $99.63 \%$. These data emphasize that this route is suitable for preparing ICCA-WFF.

\section{ICCA-WFF Forming Trimer and Having Z-Like Conformation}

FT-ICR-MS spectrum shows that the molecular assembly of ICCA-WFF leads to the formation of a trimer. ${ }^{31}$ Figure 4A shows that the FT-ICR-MS spectrum of ICCA-WFF gives an anion peak at 809.34135 (the mass of monomer minus $\mathrm{H}$, calculated value: 809.34459 ), an anion peak at 1619.69296 (the mass of dimer minus H, calculated value: 1619.69296) and an anion peak at 1214.52111 (the mass of trimer minus $2 \mathrm{H}$, calculated value: 1214.52107$)$. Figure $4 \mathrm{~B}$ shows that the qCID of the trimer minus $2 \mathrm{H}$ at 1214.52895 gives an anion peak of monomer minus $\mathrm{H}$ at 809.34930 and an anion peak of dimer minus $\mathrm{H}$ at 1619.71182 . Therefore, the anion peaks of the monomer minus $\mathrm{H}$ and the dimer minus $\mathrm{H}$ occur in Figure 4A are the fragments of the trimer, and the trimer is the sole form of ICCA-WFF to exist.

NOESY $2 \mathrm{D}{ }^{1} \mathrm{H}$ NMR spectrum and energy optimization conformation define the manner of molecular assembly of ICCA-WFF to form the trimer. ${ }^{31}$ Figure $4 \mathrm{C}$ shows that there is only one interesting cross-peak marked by a red circle. According to the concept of NOESY, this cross-peak reflects an interaction of the methine $\mathrm{H}$ of the isopropyl moiety of one molecule and the amino $\mathrm{H}$ of the carboxyl terminal Phe of Trp-Phe-Phe moiety of another molecule. This cross-peak also means that the distance between these $\mathrm{H}$ is less than $4 \AA$. Based on the distance between two $\mathrm{H}$ atoms, three energy minimized monomers of ICCA-WFF were manually
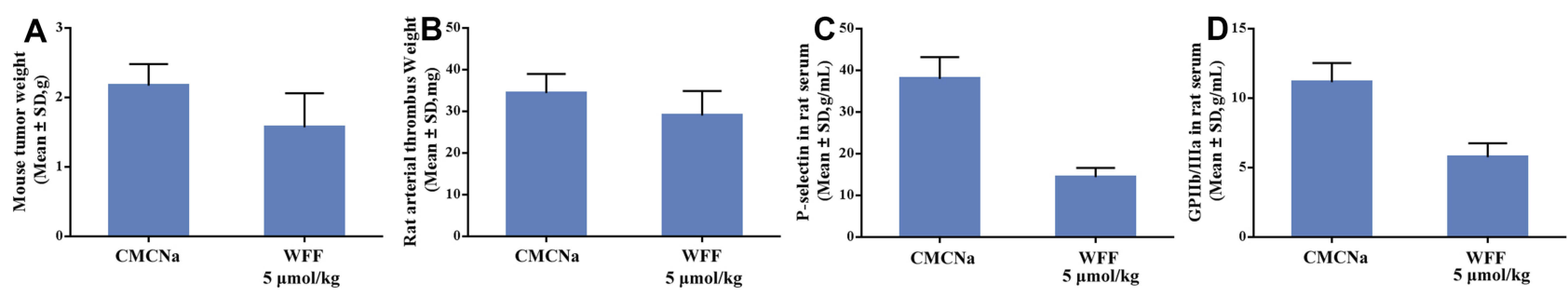

Figure I In vivo activities of Trp-Phe-Phe (WFF), $n=12$ : (A) anti-tumor activity of WFF against SI80 mice; (B) anti-thrombotic activity of WFF on rat model; (C) inhibition of WFF to serum P-selectin of arterial thrombosis rats; (D) inhibition of WFF to serum GPIIb/llla of arterial thrombosis rats.

Abbreviation: WFF, Trp-Phe-Phe. 

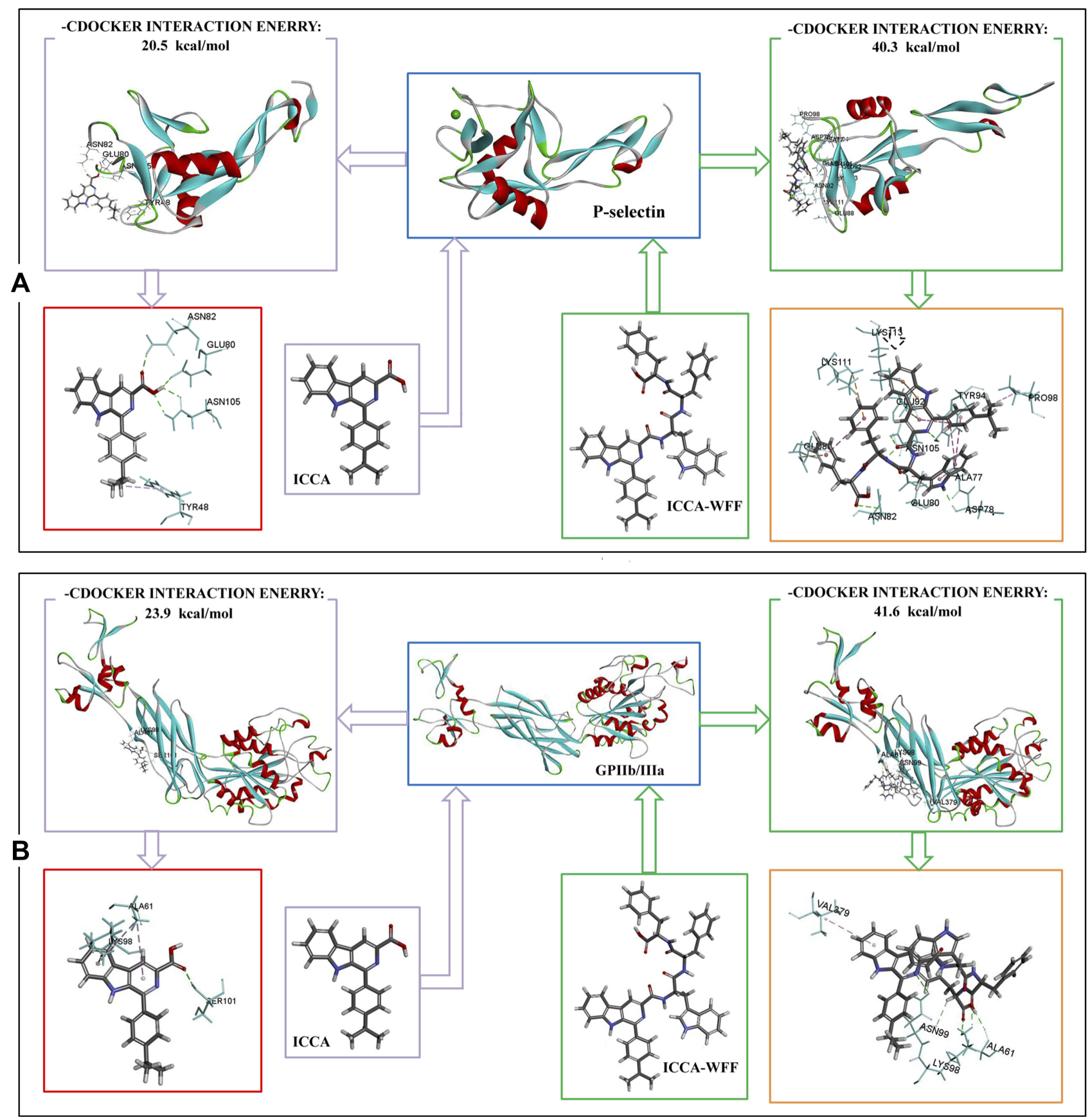

Figure 2 Docking feature of ICCA and ICCA-WFF in the active site of P-selectin and GPIIb/IIla: (A) docking feature of ICCA and ICCA-WFF in the active site of P-selectin; (B) docking feature of ICCA and ICCA-WFF in the active site of GPIIb/IIla.

Abbreviations: ICCA, I-(4-isopropylphenyl)- $\beta$-carboline-3-carboxylic acid; ICCA-WFF, I-(4-isopropylphenyl)- $\beta$-carboline-3-carbonyl-Trp-Phe-Phe.

accessed to form a trimer. This manual operation gives the trimer of ICCA-WFF a Z-like conformation (Figure 4D).

\section{Aqueous ICCA-WFF Is a Nano-Solution}

To show the nano-property of aqueous ICCA-WFF the Faraday-Tyndall effect was tested. Figure 5A, E, $\mathrm{I}$ and $\mathrm{M}$ indicate that the ultrapure water of various $\mathrm{pH}$ occurs no Faraday-Tyndall effect. Figure 5B, F,
$\mathrm{J}$ and $\mathrm{N}$ indicate that the radiation of $650 \mathrm{~nm}$ laser does not induce the ultrapure water of various $\mathrm{pH}$ to occur Faraday-Tyndall effect. Figure 5C, G, K and $\mathrm{O}$ indicate that $3.7 \mu \mathrm{M}$ solutions of ICCA-WFF in ultrapure water of various $\mathrm{pH}$ occur no FaradayTyndall effect. Figure 5D, H, L and $\mathrm{P}$ indicate that the radiation of $650 \mathrm{~nm}$ laser induces $3.7 \mu \mathrm{M}$ solutions of ICCA-WFF in ultrapure water of various $\mathrm{pH}$ to occur 


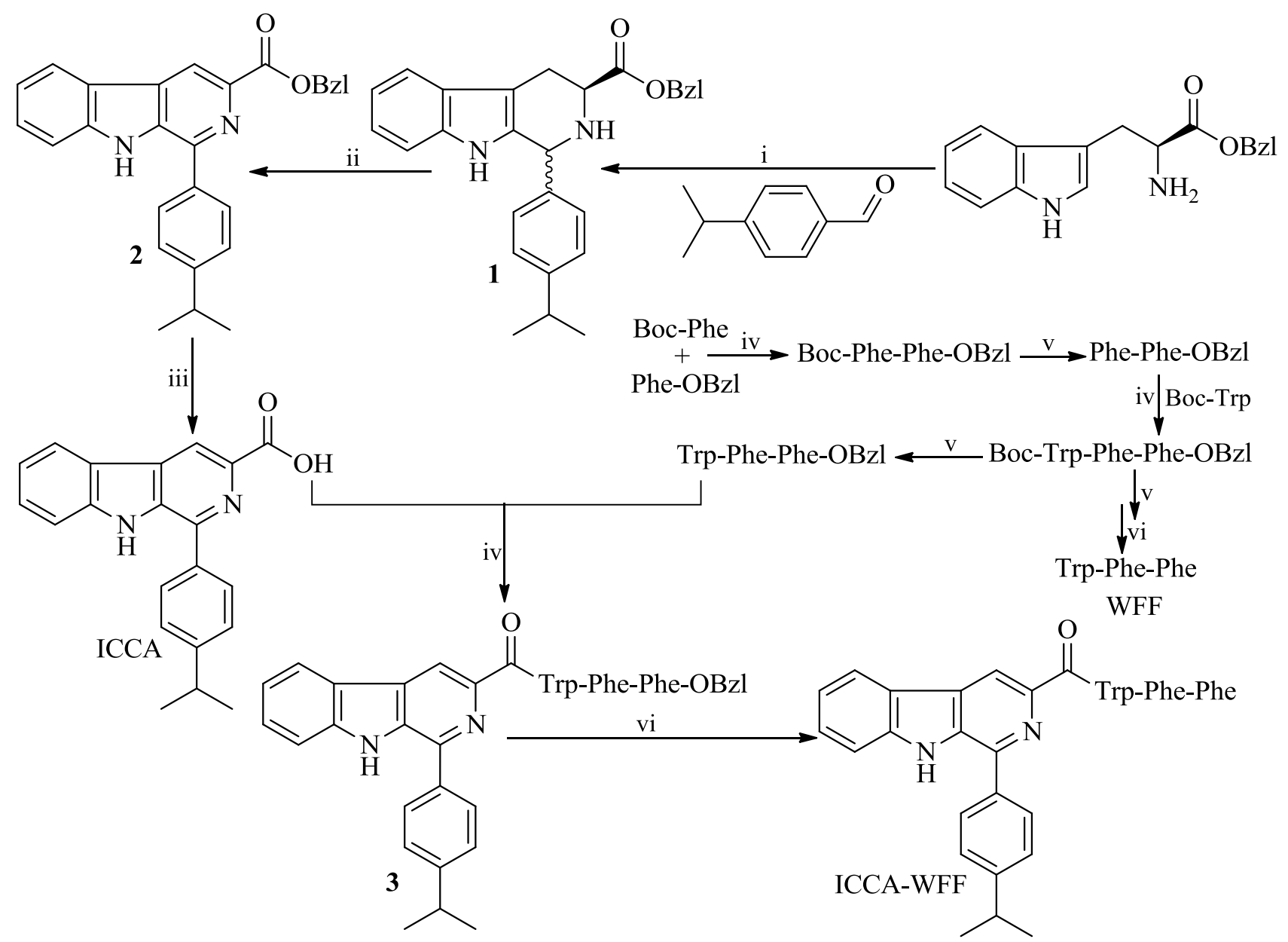

Figure 3 Synthetic route of ICCA-WFF: i) TFA, $\mathrm{CH}_{2} \mathrm{Cl}_{2}$; ii) $\mathrm{SeO}_{2}$, I,4-dioxane and $70{ }^{\circ} \mathrm{C}$; iii) aqueous $\mathrm{NaOH}(2 \mathrm{M})$, I,4-dioxane and $0^{\circ} \mathrm{C}$; iv) anhydrous THF, $\mathrm{HOBt}$, DCC; v) hydrochloride in ethyl acetate (4M); vi) $\mathrm{Pd} / \mathrm{C}$ and $\mathrm{H}_{2}$.

Abbreviations: ICCA, I-(4-isopropylphenyl)- $\beta$-carboline-3-carboxylic acid; TFA, trifluoroacetic acid; $\mathrm{CH}_{2} \mathrm{Cl}_{2}$, dichloromethane; $\mathrm{SeO}$, selenium dioxide; $\mathrm{NaOH}$, sodium hydroxide; THF, tetrahydrofuran; HOBt, I-Hydroxybenzotriazole; ICCA-WFF, I-(4-isopropylphenyl)- $\beta$-carboline-3-carbonyl-Tyr-Phe-Phe.

Faraday-Tyndall effect. These observations mean that the aqueous ICCA-WFF is nano-solution.

\section{In Aqueous Solution ICCA-WFF Exists as Nano-Particles}

To visualize the nano-feature of ICCA-WFF in the ultrapure water of $\mathrm{pH} 6.8$ the TEM images were provided. Figure 6 shows that in $1.23 \mathrm{nM}, 123 \mathrm{nM}$ and $12.3 \mu \mathrm{M}$ solutions of ICCA-WFF form nano-particles of 61.5-230.7 $\mathrm{nm}$ in diameter. Besides, the size of the nano-particles is independent of the concentration of the solution.

\section{In Solid State ICCA-WFF Exists as Nano-Particles}

To visualize the nano-feature of ICCA-WFF in solid state the lyophilized powders were prepared from solution with various concentration and $\mathrm{pH}$ values, and the SEM images of the lyophilized powders tested. Figure 7 shows that the lyophilized powders of ICCA-WFF consist of nanoparticles, the diameter of the nano-particles is less than $70 \mathrm{~nm}$, and the diameter of the nano-particles is independent of the concentration and the $\mathrm{pH}$ value of the solution used for preparing the lyophilized powders.

\section{In Rat Serum ICCA-WFF Exists as Nano-Particles}

To visualize the nano-feature of ICCA-WFF in rat plasma the AFM images were recorded. Figure 8A shows that the rat plasma alone has no interesting particles. Figure $8 \mathrm{~B}-$ D shows that in the rat plasma ICCA-WFF exists as nanoparticles of $12.3-59.2 \mathrm{~nm}$ in height, and the height is independent of the concentration. 


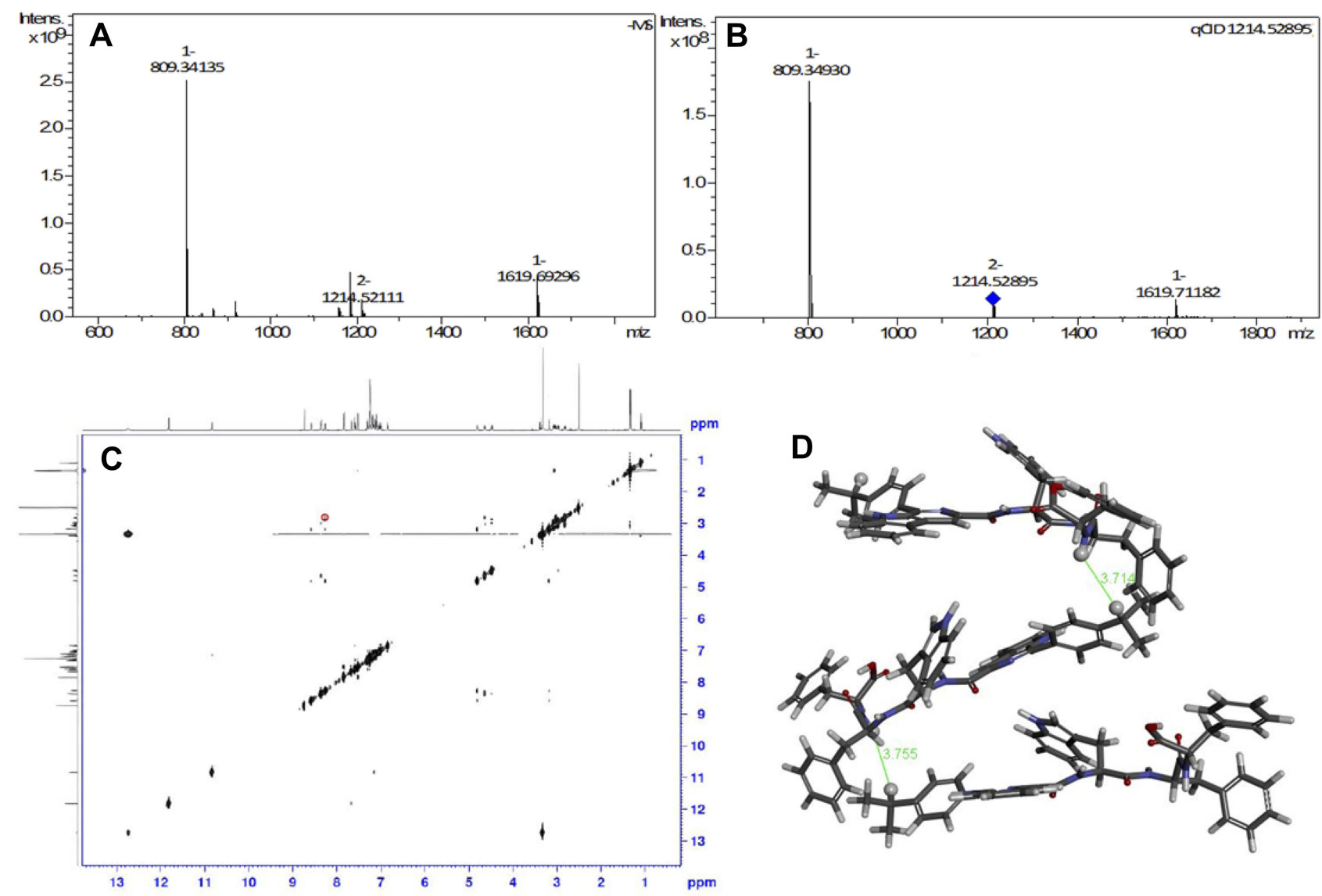

Figure 4 FT-ICR-MS spectrum, qCID, NOESY and trimer conformation of ICCA-WFF: (A) FT-ICR-MS spectrum of ICCA-WFF gives an anion peak of the monomer at 809.34I35, an anion peak of the dimer at 1619.69296 and an anion peak of the trimer at I2I4.52III; (B) qCID of the trimer at I2I4.52895 gives two anion peaks at 1619.71 82 and 809.34930; (C and D) NOESY spectrum and the manner of three-molecule-assembly of ICCA-WFF.

Abbreviations: NOESY, nuclear over hauser effect spectroscopy; ICCA-WFF, I-(4-isopropylphenyl)- $\beta$-carboline-3-carbonyl-Tyr-Phe-Phe.

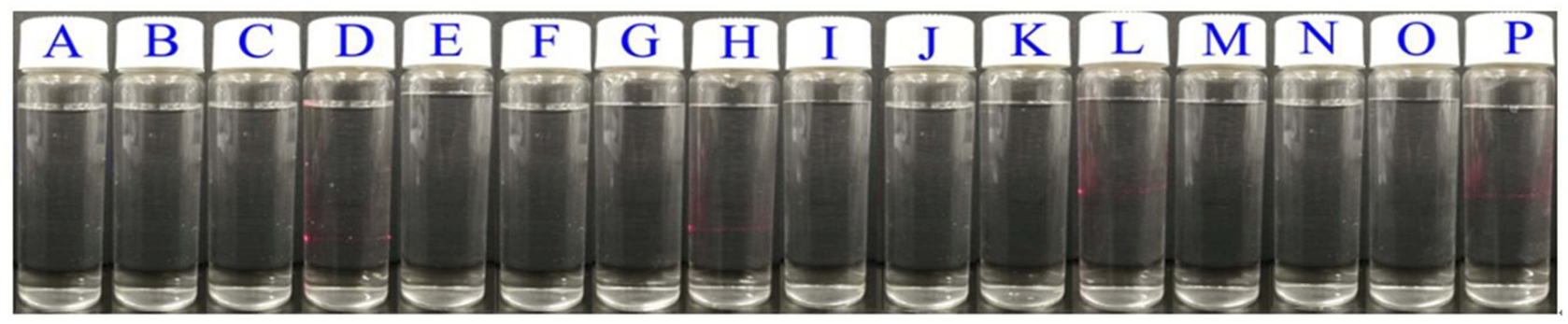

Figure 5 Tyndall effect of ICCA-WFF in various aqueous: (A) ultrapure water of $\mathrm{pH} 2.0$ without radiation; (B) ultrapure water of $\mathrm{pH} 2.0$ with $650 \mathrm{~nm}$ laser radiation; (C) $3.7 \mu$ M solution of ICCA-WFF in ultrapure water of $\mathrm{pH} 2.0$ without radiation; (D) $3.7 \mu \mathrm{M}$ solution of ICCA-WFF in ultrapure water of $\mathrm{pH} 2.0$ with $650 \mathrm{~nm}$ laser radiation; (E) ultrapure water of $\mathrm{pH} 5.8$ without radiation; (F) ultrapure water of $\mathrm{pH} 5.8$ with $650 \mathrm{~nm}$ laser radiation; (G) $3.7 \mu \mathrm{M}$ solution of ICCA-WFF in ultrapure water of $\mathrm{pH} 5.8$ without radiation; (H) $3.7 \mu \mathrm{M}$ solution of ICCA-WFF in ultrapure water of $\mathrm{pH} 5.8$ with $650 \mathrm{~nm}$ laser radiation; (I) ultrapure water of $\mathrm{pH} 6.8$ without radiation; (J) ultrapure water of $\mathrm{pH} 6.8$ with $650 \mathrm{~nm}$ laser radiation; (K) $3.7 \mu \mathrm{M}$ solution of ICCA-WFF in ultrapure water of $\mathrm{pH} 6.8$ without radiation; $(\mathbf{L}) 3.7 \mu$ M solution of ICCA-WFF in ultrapure water of $\mathrm{pH} 6.8$ with $650 \mathrm{~nm}$ laser radiation; (M) ultrapure water of $\mathrm{pH} 7.4$ without radiation; $(\mathbf{N})$ ultrapure water of $\mathrm{pH} 7.4$ with $650 \mathrm{~nm}$ laser radiation; (O) $3.7 \mu \mathrm{M}$ solution of ICCA-WFF in ultrapure water of $\mathrm{pH} 7.4$ without radiation; $(\mathbf{P}) 3.7 \mu \mathrm{M}$ solution of ICCA-WFF in ultrapure water of $\mathrm{pH} 7.4$ with $650 \mathrm{~nm}$ laser radiation.

Abbreviation: ICCA-WFF, I-(4-isopropylphenyl)- $\beta$-carboline-3-carbonyl-Tyr-Phe-Phe.

\section{ICCA-WFF Has Similar Cytotoxicity to ICCA in vitro}

To know if the modification of ICCA by Trp-Phe-Phe greatly alters the cytotoxicity of ICCA, the viabilities of A549, 95D, K562 and S180 cells treated by ICCA-WFF were measured by using
MTT method. ${ }^{22}$ Figure 9 shows that the $\mathrm{IC}_{50}$ values of ICCAWFF against A549, K562, S180 and 95D cells are $\sim 50-100 \mu \mathrm{M}$. The $\mathrm{IC}_{50}$ of ICCA-WFF against $95 \mathrm{D}$ cells has the lowest value. In was known that the $\mathrm{IC}_{50}$ values of ICCA against A549, K562, S180 and 95D cells are also $\sim 50-100 \mu \mathrm{M} .^{22}$ Thus, for these cells, 


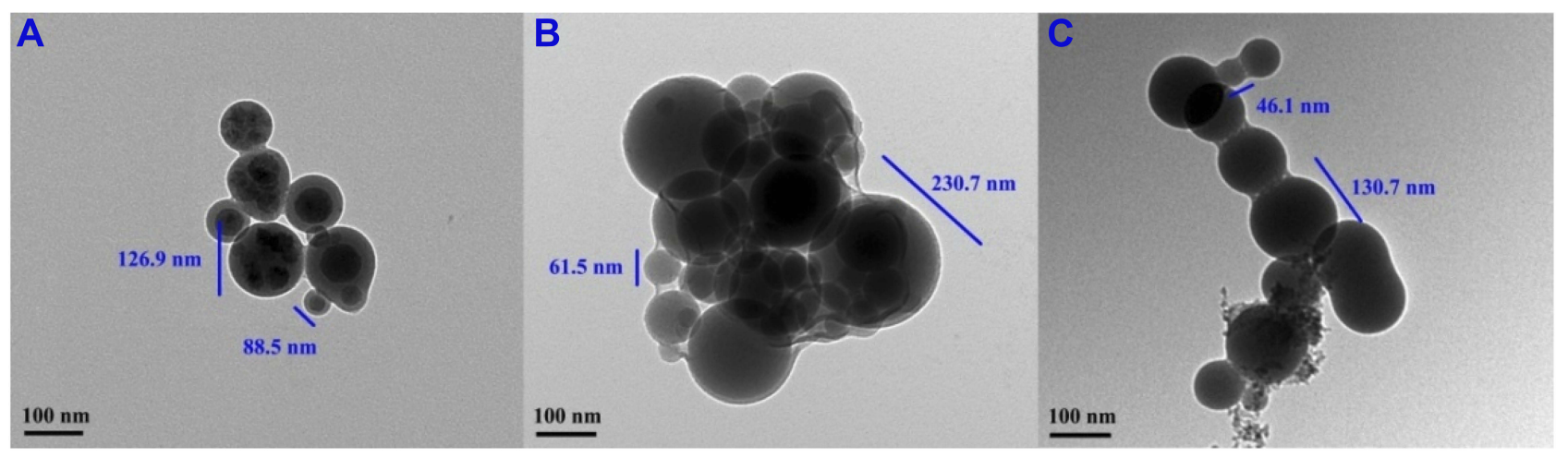

Figure 6 TEM images of ICCA-WFF in ultrapure water: (A) TEM image of $12.3 \mu \mathrm{M}$ ICCA-WFF in ultrapure water of $\mathrm{pH} 6.8$; (B) TEM image of I23 nM ICCA-WFF in ultrapure water of $\mathrm{pH} 6.8$; (C) TEM image of $1.23 \mathrm{nM}$ ICCA-WFF in ultrapure water of $\mathrm{pH} 6.8$.

Abbreviations: TEM, transmission electron microscopy; ICCA-WFF, I-(4-isopropylphenyl)- $\beta$-carboline-3-carbonyl-Tyr-Phe-Phe.

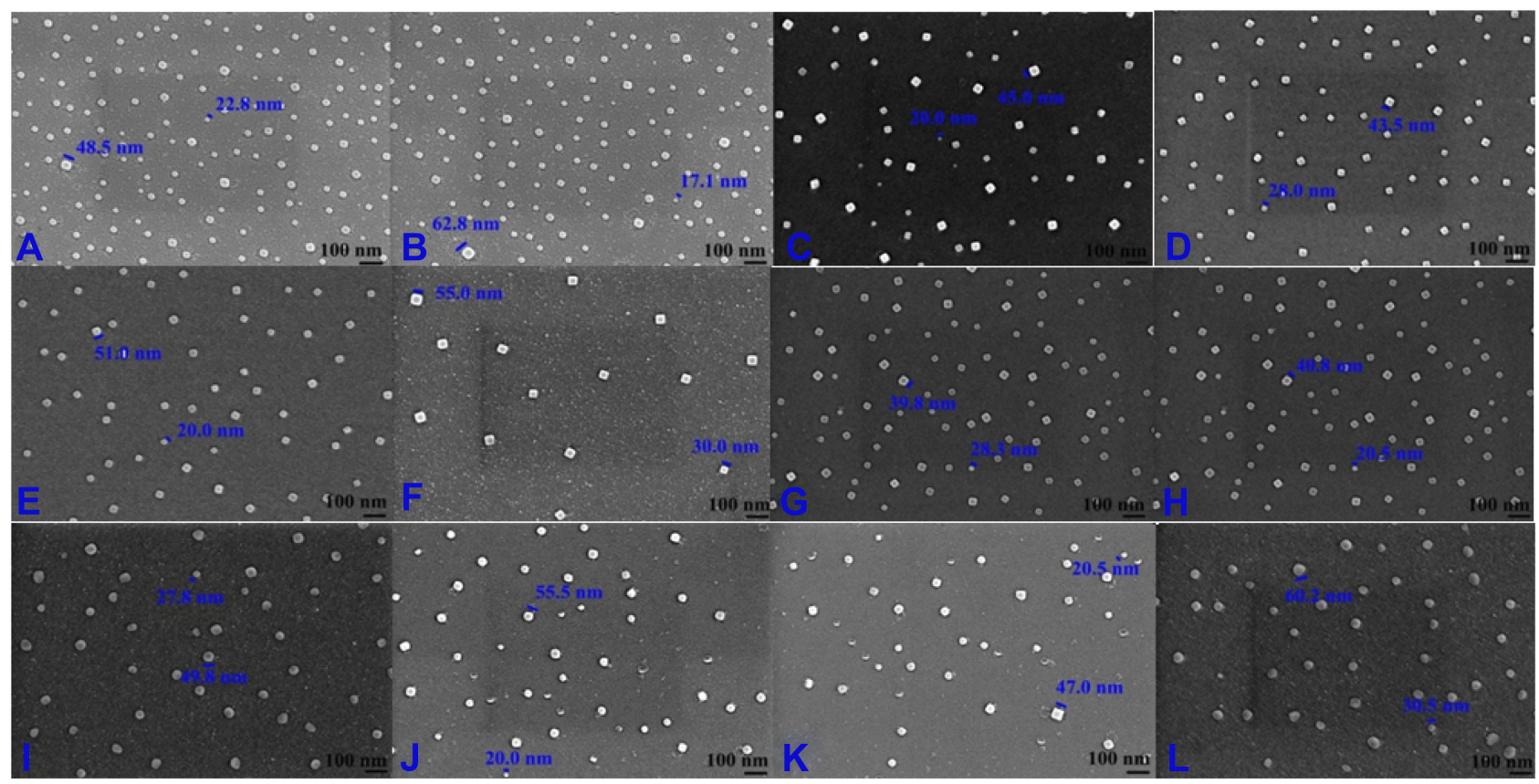

Figure 7 SEM images of lyophilized powders of ICCA-WFF: (A) SEM image of the lyophilized powders prepared from a solution of ICCA-WFF in ultrapure water of pH 2.0 (I2.3 $\mu$ M); (B) SEM image of the lyophilized powders prepared from a solution of ICCA-WFF in ultrapure water of $\mathrm{pH} 2.0$ (I23 nM); (C) SEM image of the lyophilized powders prepared from a solution of ICCAWFF in ultrapure water of $\mathrm{pH} 2.0$ (I.23 nM); (D) SEM image of the lyophilized powders prepared from a solution of ICCA-WFF in ultrapure water of pH 5.8 (I2.3 $\mu$ M); (E) SEM image of the lyophilized powders prepared from a solution of ICCA-WFF in ultrapure water of $\mathrm{pH} 5.8$ (I23 nM); (F) SEM image of the lyophilized powders prepared from a solution of ICCA-WFF in ultrapure water of $\mathrm{pH} 5.8$ (I.23 nM); (G) SEM image of the lyophilized powders prepared from a solution of ICCA-WFF in ultrapure water of pH 5.8 (I2.3 $\mu$ M); (H) SEM image of the lyophilized powders prepared from a solution of ICCA-WFF in ultrapure water of $\mathrm{pH} 6.8$ (I23 nM); (I) SEM image of the lyophilized powders prepared from a solution of ICCA-WFF in ultrapure water of $\mathrm{pH} 6.8$ (I.23 nM); (J) SEM image of the lyophilized powders prepared from a solution of ICCA-WFF in ultrapure water of pH 7.4 (I2.3 $\mu$ M); (K) SEM image of the lyophilized powders prepared from a solution of ICCA-WFF in ultrapure water of $\mathrm{pH} 7.4$ (I23 nM); (L) SEM image of the lyophilized powders prepared froma solution of ICCA-WFF in ultrapure water of pH 7.4 (I.23 $\mathrm{nM}$ ). Abbreviations: SEM, scanning electron microscopy; ICCA-WFF, I-(4-isopropylphenyl)- $\beta$-carboline-3-carbonyl-Tyr-Phe-Phe.

ICCA-WFF and ICCA have similar $\mathrm{IC}_{50}$, and Trp-Phe-Phe modification does not greatly alter the cytotoxicity of ICCA.

\section{Trp-Phe-Phe Modification Increases Anti-Tumor Activity of ICCA in vivo}

To evidence the enhanced the antitumor activity of TrpPhe-Phe modification of ICCA in vivo the tumor growth assay was performed on S180 mouse model. ${ }^{22}$ Figure $10 \mathrm{~A}$ shows that the tumor weight of S180 mice orally treated with $5 \mu \mathrm{mol} / \mathrm{kg} /$ day of ICCA for 9 consecutive days is significantly lower than that of S180 mice orally treated with CMCNa. Figure 10A also shows that ICCA-WFF dose-dependently slows tumor growth, and the tumor weight of S180 mice orally treated with $0.5 \mu \mathrm{mol} / \mathrm{kg} /$ day 

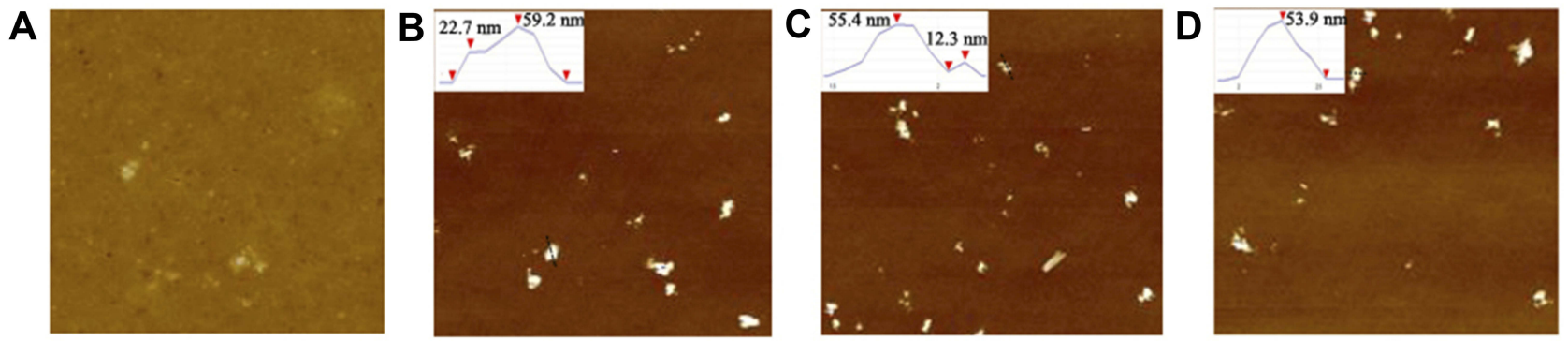

Figure 8 AFM images of ICCA-WFF in rat serum: (A) AFM image of rat serum alone; (B) AFM image of ICCA-WFF in rat serum (I.2× $\left.0^{-2} \mathrm{nM}\right)$; (C) AFM image of ICCAWFF in rat serum $\left(1.2 \times 10^{-3} \mathrm{nM}\right)$; (D) AFM image of ICCA-WFF in rat serum $\left(1.2 \times 10^{-4} \mathrm{nM}\right)$.

Abbreviations: AFM, atomic force microscopy; ICCA-WFF, I-(4-isopropylphenyl)- $\beta$-carboline-3-carbonyl-Tyr-Phe-Phe.



Figure 9 Effect of ICC-WFF on cell viability $(n=5)$.

of ICCA-WFF for 9 consecutive days is equal to that of S180 mice orally treated with $5 \mu \mathrm{mol} / \mathrm{kg} /$ day of ICCA. Therefore, Trp-Phe-Phe modification leads the anti-tumor activity of ICCA to 10 -fold increase.

\section{Trp-Phe-Phe Modification Increases the Inhibition of ICCA to Arterial Thrombosis in vivo}

To evidence the enhanced anti-thrombotic activity of TrpPhe-Phe modification of ICCA in vivo the arterial thrombotic assays were performed on mouse and rat models. ${ }^{22}$ Figure 10B shows that ICCA-WFF dose-dependently decreases the arterial thrombus weight of the mice, and the arterial thrombus weight of the mice orally treated by 0.5 $\mu \mathrm{mol} / \mathrm{kg}$ of ICCA-WFF is equal to that of the mice orally treated by $5 \mu \mathrm{mol} / \mathrm{kg}$ of ICCA. Therefore, Trp-Phe-Phe modification leads the anti-thrombotic activity of ICCA for mice to 10 -fold increase. Figure 10C shows that ICCA-WFF dosedependently decreases the arterial thrombus weight of the rats, and the arterial thrombus weight of the rats orally treated by $0.05 \mu \mathrm{mol} / \mathrm{kg}$ of ICCA-WFF is equal to that of the rats orally treated by $5 \mu \mathrm{mol} / \mathrm{kg}$ of ICCA. Therefore, Trp-PhePhe modification leads the anti-thrombotic activity of ICCA for rats having a 100-fold increase.

\section{Trp-Phe-Phe Modification Does Not increase the Inhibition of ICCA to Venous Thrombosis in vivo}

To show the effect of Trp-Phe-Phe modification on the antivenous thrombotic activity of ICCA the venous thrombotic assays were performed on rat models. ${ }^{22}$ Figure 10D shows that ICCA-WFF dose-dependently decreases the venous thrombus weight of the treated rats, and the minimal effective dose is $0.5 \mu \mathrm{mol} / \mathrm{kg}$. Besides, at $5 \mu \mathrm{mol} / \mathrm{kg}$ of dose ICCAWFF, ICCA and warfarin have equal activity. This means that Trp-Phe-Phe modification does not enhance the inhibition of ICCA to venous thrombosis in vivo.

\section{ICCA-WFF Down regulates $P$-selectin and GPIlb/llla Expression in vivo}

To correlate P-selectin and GPIIb/IIIa with the inhibition of ICCA-WFF to arterial thrombosis in vivo the expression levels of P-selectin and GPIIb/IIIa were examined by using the reported methods. ${ }^{22}$ Figure $11 \mathrm{~A}$ shows that P-selectin level in the serum of the rats treated with $5 \mu \mathrm{mol} / \mathrm{kg}$ ICCA is significantly lower than that of the rats treated with $\mathrm{CMCNa}$, and is significantly higher than that of the rats treated with 5 $\mu \mathrm{mol} / \mathrm{kg} \quad$ ICCA-WFF. Thus, by downregulating P-selectin expression ICCA-WFF inhibits arterial thrombosis. Figure 11B shows that GPIIb/IIIa level in the serum of the rats treated with $5 \mu \mathrm{mol} / \mathrm{kg}$ ICCA is significantly lower than that of the rats treated with $\mathrm{CMCNa}$, and is significantly higher than that of the rats treated with $5 \mu \mathrm{mol} / \mathrm{kg}$ ICCA-WFF. Thus, by downregulating GPIIb/IIIa expression ICCA-WFF 
A

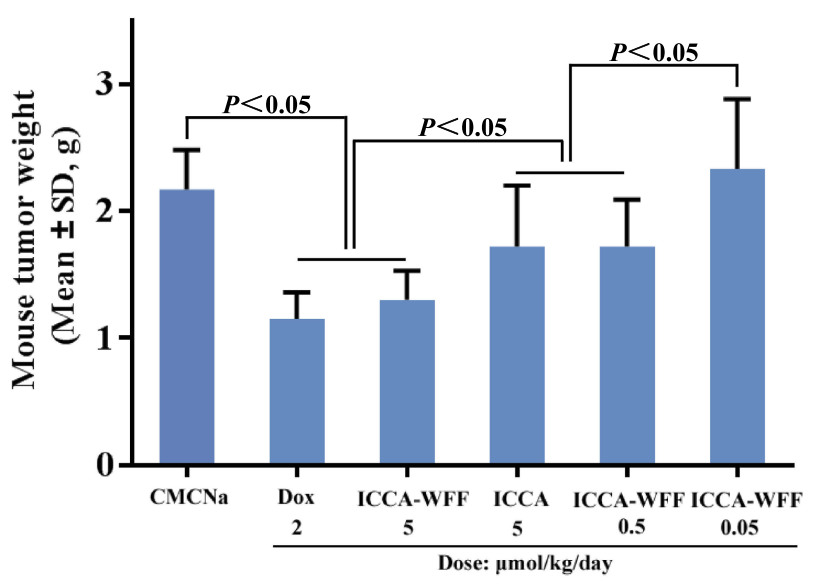

C

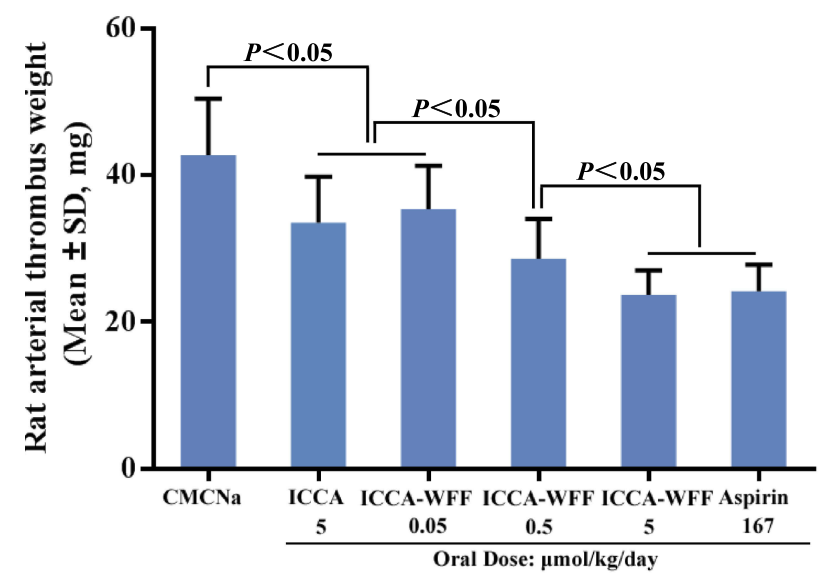

B

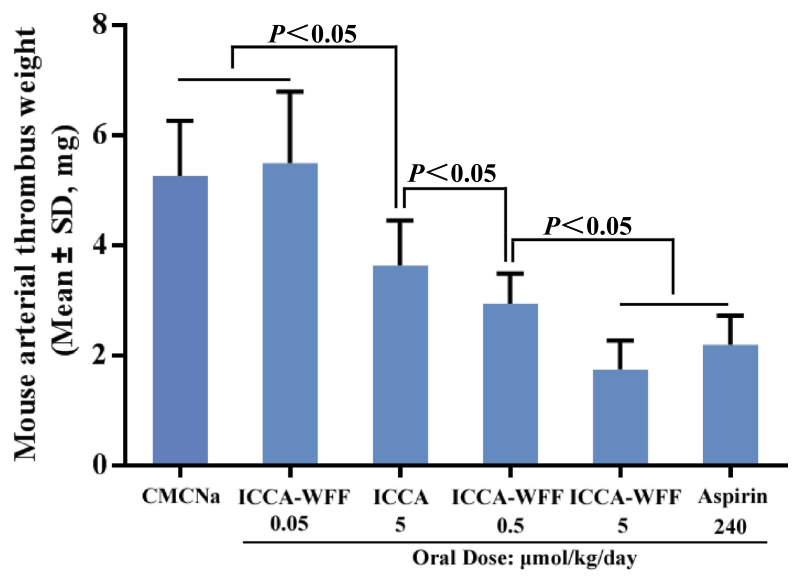

D

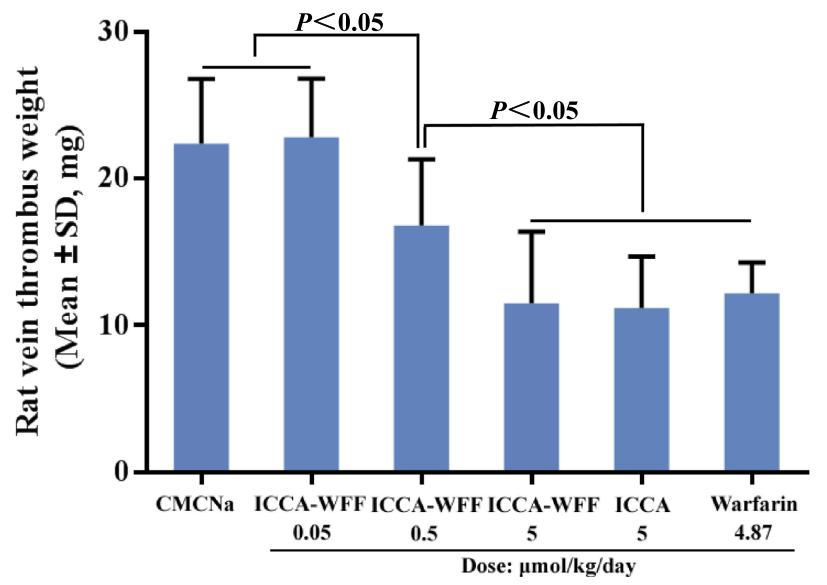

Figure 10 Activity of ICCA-WFF in vivo assays $(n=12)$ : (A) anti-tumor activity of ICCA-WFF; (B) activity of ICCA-WFF in mouse arterial thrombotic assay; (C) activity of ICCA-WFF in rat arterial thrombotic assay; (D) activity of ICCA-WFF in rat vein thrombotic assay.

Abbreviations: CMCNa, carboxymethylcellulose sodium; Dox, doxorubicin; ICCA, I-(4-isopropylphenyl)- $\beta$-carboline-3-carboxylic acid; ICCA-WFF, I-(4-isopropylphenyl)$\beta$-carboline-3-carbonyl-Tyr-Phe-Phe.
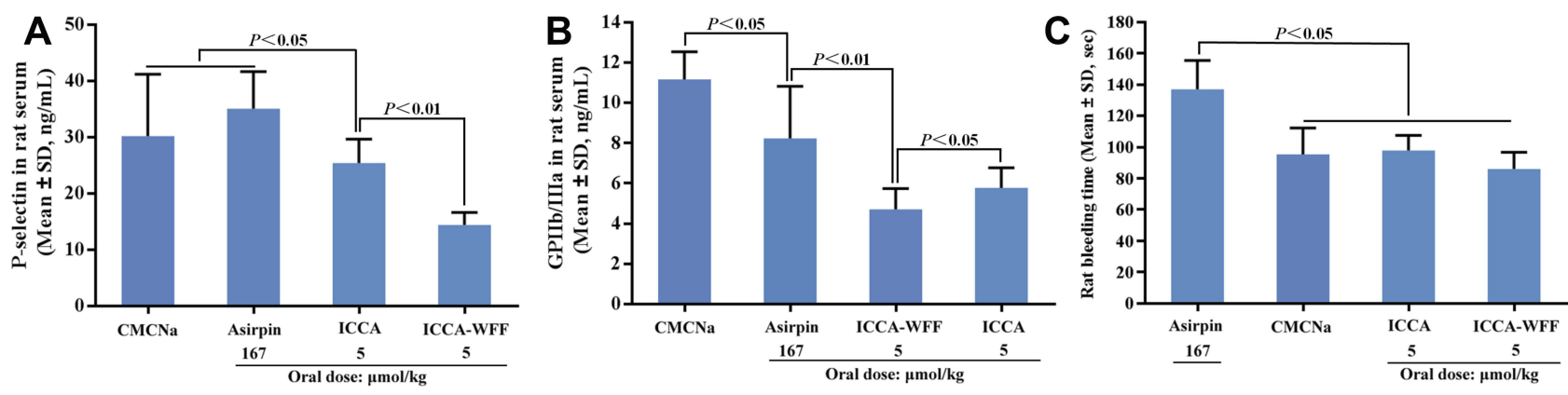

Figure II Expression of P-selectin and GPIIb/llla, as well as tail bleeding time of ICCA-WFF-treated rats in arterial thrombotic assays ( $\mathrm{n}=$ I2): (A) ICCA-WFF downregulates P-selectin expression; (B) ICCA-WFF down-regulates GPIIb/Illa expression; (C) ICCA-WFF does not increase bleeding risk of ICCA.

Abbreviations: CMCNa, carboxymethyl cellulose sodium; ICCA, I-(4-isopropylphenyl)- $\beta$-carboline-3-carboxylic acid; ICCA-WFF, I-(4-isopropylphenyl)- $\beta$-carboline-3-carbonyl-Tyr-Phe-Phe.

effectively inhibits arterial thrombosis. Besides, the efficacy of ICCA-WFF downregulating the expression of P-selectin and GPIIb/IIIa is 33 folds higher than that of aspirin.

\section{ICCA-WFF Has No Bleeding Risk}

To show the bleeding risk of ICCA-WFF the rats of arterial thrombosis assay to be given tail bleeding time assay by using the reported method. ${ }^{28}$ Figure $11 \mathrm{C}$ shows 
that at $5 \mu \mathrm{mol} / \mathrm{kg}$ of oral dose both ICCA and ICCAWFF do not prolong tail bleeding time of the treated rats. Thus, Trp-Phe-Phe modification does not increase the bleeding risk of ICCA. Besides, the tail bleeding time of the rats treated by $167 \mu \mathrm{mol} / \mathrm{kg}$ of aspirin is significantly longer than that of the rats treated by 5 $\mu \mathrm{mol} / \mathrm{kg}$ of ICCA-WFF.

\section{By Adhering Rat Platelets ICCA-WFF Inhibits P-selectin and GPIIb/IIla \\ Expression}

The in vitro action of ICCA-WFF on the resting rat platelets and arachidonic acid (AA) activated rat platelets was visualized by AFM. Figure 12A shows that the resting rat platelets have a smooth surface and have no pseudopodia. Figure 12B-D shows that in the presence of ICCA-WFF $\left(1.2 \times 10^{-2} \mathrm{nM}, 1.2 \times 10^{-3} \mathrm{nM}\right.$ and $\left.1.2 \times 10^{-4} \mathrm{nM}\right)$ the resting rat platelets neither have smooth surface nor have pseudopodium. Figure 12E shows that the activation of AA induces rat platelets to extend pseudopodia and to form aggregation. Figure $12 \mathrm{~F}-\mathrm{H}$ show that ICCA-WFF concentration $\left(1.2 \times 10^{-2}\right.$ $\mathrm{nM}, 1.2 \times 10^{-3} \mathrm{nM}$ and $\left.1.2 \times 10^{-4} \mathrm{nM}\right)$ dependently inhibits AA activated rat platelets to extend pseudopodia and to form aggregation. These phenomena suggest that by adhering onto the surfaces of the rat platelets, ICCA-WFF downregulates the expression of P-selectin and GPIIb/IIIa.

\section{Mesoscale Simulation of ICCA-WFF Forming Nano-Particle}

To dissect the process of the nano-particle formation and to predict the molecular number of ICCA-WFF in a nano-particle of definite diameter a mesoscale simulation was performed. Figure 13 shows that the formation of the nano-particle consists of 3 steps, and a nano-particle of $99.96 \mathrm{~nm}$ in diameter contains 1187 molecules of ICCA-WFF. This demonstrates that mesoscale simulation not only reveals the course of nano-particle formation but also estimates how much molecules will be involved in a nano-particle of the exact size.

\section{ICCA-WFF Has No Liver and Renal Toxicity}

Serum ALT, AST, Cr and BUN are usually for estimating the toxicity of the drug to kidney and liver. ${ }^{25}$ In this profile, the ALT, AST, Cr and BUN of S180 mice treated with $5 \mu \mathrm{mol} /$ $\mathrm{kg}$ /day of ICCA-WFF or CMCNa for 9 consecutive days were measured and are shown in Figure 14A. As seen, the
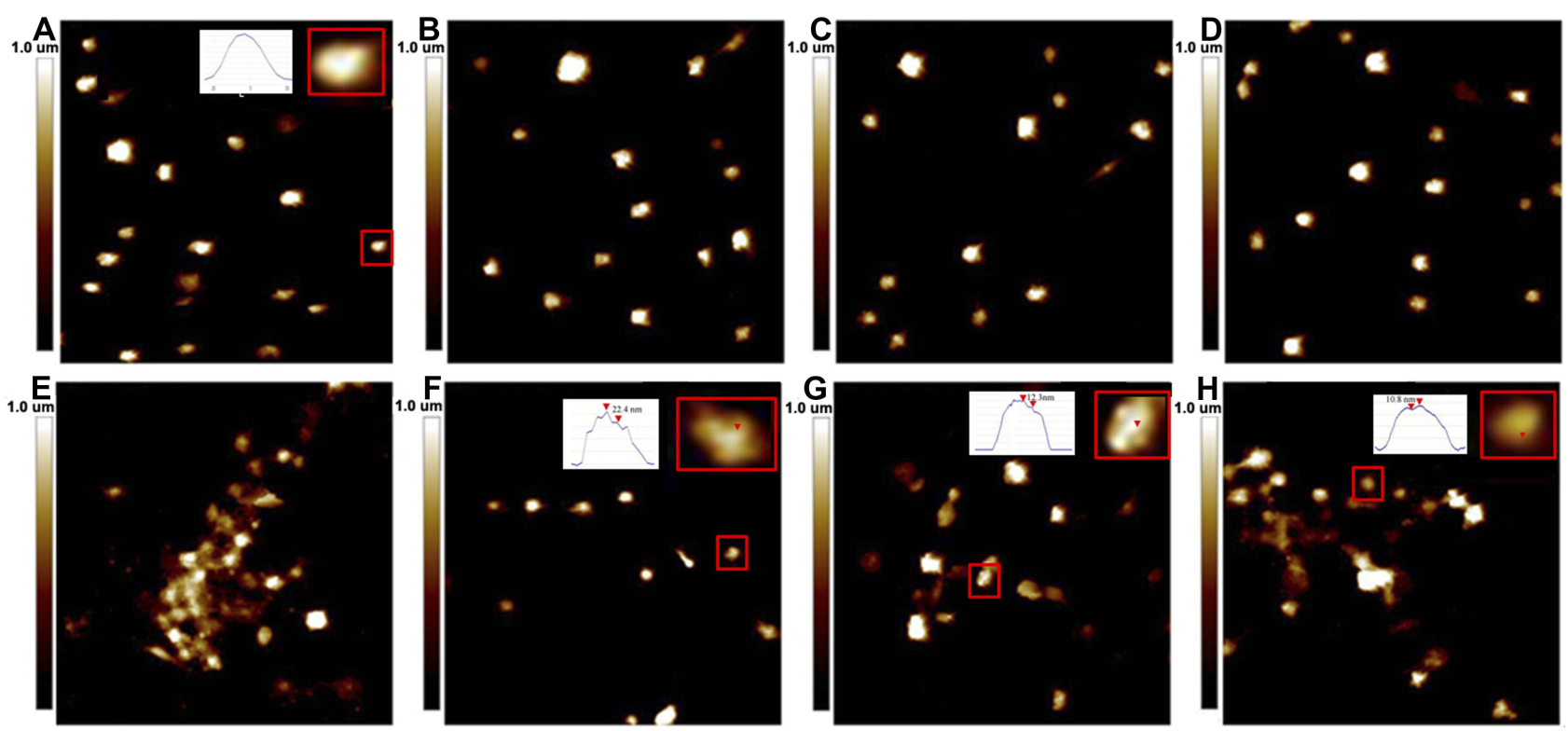

Figure 12 Imaging the interaction of ICCA-WFF and rat platelets by AFM: (A) AFM image of resting rat platelets; (B) AFM image of resting rat platelets with ICCA-WFF $\left(1.2 \times 10^{-2} \mathrm{nM}\right)$; (C) AFM image of resting rat platelets with ICCA-WFF $\left(1.2 \times 10^{-3} \mathrm{nM}\right)$; (D) AFM image of resting rat platelets with ICCA-WFF (I.2× $\left.10^{-4} \mathrm{nM}\right)$; (E) AFM image of AA activated rat platelets; (F) AFM image of AA activated rat platelets with ICCA-WFF $\left(1.2 \times 10^{-2} \mathrm{nM}\right)$; (G) AFM image of AA activated rat platelets with ICCA-WFF $\left(1.2 \times 10^{-3} \mathrm{nM}\right) ;(\mathbf{H})$ AFM image of AA activated rat platelets with ICCA-WFF $\left(1.2 \times 10^{-4} \mathrm{nM}\right)$.

Abbreviations: AFM, atomic force microscopy; ICCA-WFF, I-(4-isopropylphenyl)- $\beta$-carboline-3-carbonyl-Tyr-Phe-Phe; AA, arachidonic acid. 




Figure 13 The course of forming nano-particle explored by mesoscale simulation and the molecular number of ICCA-WFF in a nano-particle of definite diameter. Abbreviation: ICCA-WFF, I-(4-isopropylphenyl)- $\beta$-carboline-3-carbonyl-Tyr-Phe-Phe.

ALT, AST, Cr and BUN of S180 mice treated by ICCA-WFF are equal to those of $\mathrm{S} 180$ mice treated by $\mathrm{CMCNa}$. These data mean that, similarly to $\mathrm{CMCNa}, 5 \mu \mathrm{mol} / \mathrm{kg}$ of ICCAWFF does not injure the kidney and the liver of S180 mice.

\section{ICCA-WFF Affects No Coagulation}

\section{Function}

To estimate the effect of ICCA-WFF on coagulation function the PT, TT, APTT and FIB of the rats in the venous thrombosis assay were measured. Figure 14B shows that the PT, TT, APTT and FIB of the rats treated by ICCA-WFF ( $5 \mu \mathrm{mol} / \mathrm{kg}, 12$ rats $)$ are equal to those of the rats treated by $\mathrm{CMCNa}(3 \mathrm{~mL} / \mathrm{kg}$, negative control, 12 rats). The PT, TT, APTT and FIB suggest that, similarly to $\mathrm{CMCNa}, 5 \mu \mathrm{mol} / \mathrm{kg}$ of ICCA-WFF does not injure the coagulation system of the thrombosis rats. ${ }^{22}$

\section{ICCA-WFF Targets Arterial Thrombus and Tumor Tissue}

To ensure the targeting action and release the extracts of the homogenates of the blood, brain, heart, kidney, liver, spleen, arterial thrombus or venous thrombus of the rats treated with CMCNa or ICCA-WFF ( $5 \mu \mathrm{mol} / \mathrm{kg})$, as well as the extracts of the homogenates of the blood, brain, heart, kidney, liver, spleen and the tumor tissue of $\mathrm{S} 180$ mice treated with CMCNa or ICCA-WFF ( $5 \mu \mathrm{mol} / \mathrm{kg} /$ day) received FT-ICRMS spectrum analysis. It was found that the FT-ICR-MS spectra of the extract of the homogenate of the arterial thrombus, but not the blood and the organs, of the arterial thrombosis rats treated by ICCA-WFF gave the ion peas related to ICCA-WFF. It was also found that the FT-ICRMS spectra of the extract of the homogenate of the venous thrombus, but not the blood and the organs, of the venous thrombosis rats treated by ICCA-WFF gave the ion peas related to ICCA-WFF. It was again found that the FT-ICRMS spectra of the extract of the homogenate of the tumor tissue, but not the blood and the organs, of the S180 mice treated by ICCA-WFF gave the ion peas related to ICCAWFF. These observations are shown in Figure 15.

Figure 15A and B are the FT-ICR-MS spectra of the extracts of the homogenates of the arterial thrombus and the venous thrombus, respectively. In both of the spectra,
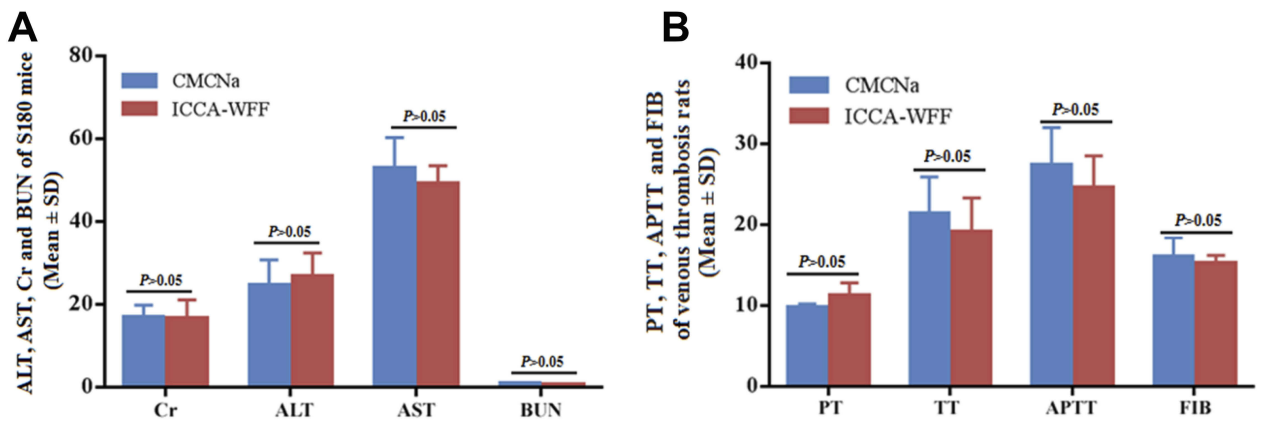

Figure I4 Effects of ICCA-WFF on the kidney and the liver of SI80 mice $(n=I 2)$ as well as the coagulation system of the venous thrombosis rats ( $n=I 2)$ : $(A)$ effect of ICCAWFF on the kidney and the liver of SI80 mice; (B) effect of ICCA-WFF on the coagulation system of the venous thrombosis rats.

Abbreviations: ALT, glutamic pyruvictran-saminase; AST, glutamic oxaloacetic transaminase; Cr, creatinine; BUN, blood urea nitrogen; FIB, fibrinogen; PT, prothrombin time; TT, thrombin time; APTT, activated partial thromboplastin time; CMCNa, carboxymethyl cellulose sodium; ICCA-WFF, I-(4-isopropylphenyl)- $\beta$-carboline-3-carbonylTyr-Phe-Phe. 

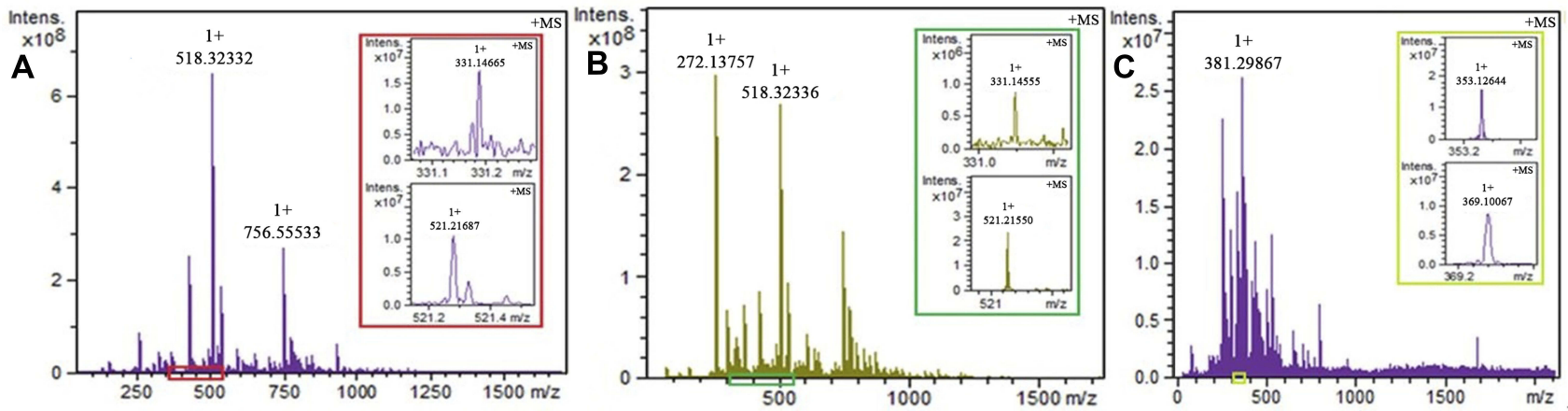

Figure I5 FT-ICR-MS spectra of the homogenate extracts of the arterial thrombus and venous thrombus of the rats treated with $5 \mu \mathrm{mol} / \mathrm{kg}$ of ICCA-WFF: (A) FT-ICR-MS spectrum of the homogenate extract of arterial thrombus of the rats treated with $5 \mu \mathrm{mol} / \mathrm{kg}$ of ICCA-WFF, in the local amplified inset an ion peak of ICCA plus $\mathrm{H}$ is at 33I.I4555 (calculated value: 33I.14465) and an ion peak of Trp-Phe-Phe plus $\mathrm{Na}$ is at 52I.2I687 (calculated value: 52I.2I648); (B) FT-ICR-MS spectrum of the homogenate extract of venous thrombus of the rats treated with $5 \mu \mathrm{mol} / \mathrm{kg}$ of ICCA-WFF, in the local amplified inset an ion peak of ICCA plus $\mathrm{H}$ is at $33 \mathrm{I}$.I4665 (calculated value: 33I.14465) and an ion peak of Trp-Phe-Phe plus $\mathrm{Na}$ is at 52I.21550 (calculated value: 521.21648); (C) FT-ICR-MS spectrum of the homogenate extract of tumor tissue of SI 80 mice treated with $5 \mu \mathrm{mol} / \mathrm{kg}$ of ICCA-WFF, in the local amplified inset an ion peak of ICCA plus Na is at 353.12644 (calculated value: 353.12660 ) and an ion peak of ICCA plus $\mathrm{K}$ is at 369.10067 (calculated value: 369.10053 ).

Abbreviations: ICCA, I-(4-isopropylphenyl)- $\beta$-carboline-3-carboxylic acid; ICCA-WFF, I-(4-isopropylphenyl)- $\beta$-carboline-3-carbonyl-Tyr-Phe-Phe.

there are the ion peaks of ICCA and Trp-Phe-Phe. These data evidence that ICCA-WFF targets thrombus and releases antithrombus pharmacophores ICCA and Trp-Phe-Phe. Figure $15 \mathrm{C}$ is FT-ICR-MS spectrum of the extract of the homogenate of the tumor tissue. In the spectrum, there is the ion peak of ICCA. This data evidences that ICCA-WFF targets tumor tissue and releases anti-tumor pharmacophore ICCA.

\section{ICCA-WFF Enters Cytoplasm of 95D Cells}

To show the cellular uptake of ICCA-WFF the confocal microscope images of 95D cells treated by complete RPMI 1640 medium and ICCA-WFF $(55 \mu \mathrm{M}, 27.5 \mu \mathrm{M}$ and $13.5 \mu \mathrm{M})$ were recorded, and the images are visualized. Figure $16 \mathrm{~A}$ shows that at $405 \mathrm{~nm}$ of excitation wavelength and $575 \mathrm{~nm}$ of emission wavelength the nucleus of the cells treated by the complete RPMI 1640 medium exhibits weak red. Figure $16 \mathrm{~B}-\mathrm{D}$ show that at $405 \mathrm{~nm}$ of excitation wavelength and $575 \mathrm{~nm}$ of emission wavelength the cytoplasm, but not nucleus of the cells, treated by ICCA-WFF exhibits strong red. This strong red is from the UV absorption of ICCA-WFF at $254 \mathrm{~nm}$, and the absorption strength depends on the concentration of ICCA-WFF. Thus, confocal microscope images reflect the uptake of ICCA-WF for 95D cells in a concentration-dependent manner.

\section{Discussion}

The synthetic route of Figure 2 provides ICCA-WFF in proper yield and high HPLC purity. These results demonstrate that the route is suitable for preparing ICCA-WFF. FT-


Figure 16 Confocal microscope images of 95D cells treated by complete RPMI 1640 medium or ICCA-WFF; (A) confocal microscope images of 95D cells treated by complete RPMI 1640 medium; (B) confocal microscope images of 95D cells treated by $55 \mu$ M ICCA-WFF; (C) confocal microscope images of $95 \mathrm{D}$ cells treated by $27.5 \mu \mathrm{M}$ ICCA-WFF; (D) confocal microscope images of 95D cells treated by I3.5 $\mu$ M ICCA-WFF; $n=3$.

Abbreviation: ICCA-WFF, I-(4-isopropylphenyl)- $\beta$-carboline-3-carbonyl-Tyr-Phe-Phe. 
ICR-MS spectrum approves that due to molecular assembly the trimer is the sole existence form of ICCA-WFF. To explore whether the trimer can further assemble the aqueous ICCA-WFF is radiated with $650 \mathrm{~nm}$ laser to test FaradayTyndall effect. The appearance of Faraday-Tyndall effect suggests that aqueous ICCA-WFF has nano-property and this nano-property should contribute to the assembly of ICCA-WFF's trimer. The assembly of the trimer is further visualized with TEM, ESM and AFM images. The images show that even though in ultrapure water of $\mathrm{pH} 6.8$ the diameter of the nano-particles is $61.5-230.7 \mathrm{~nm}$, in the lyophilized powders, the diameter of the nano-particles is less than $70 \mathrm{~nm}$ and in rat plasma the height of the nanoparticles is less than $60 \mathrm{~nm}$ in particular. The size of the nanoparticles suggests that in the blood circulation ICCAWFF is able to avoid macrophage phagocytosis and is capable of safe delivery. AFM images also visualize that the size of the nano-particles benefits ICCA-WFF adhering onto the surfaces of AA activated rat platelets. Logically, this kind of adhering property benefits ICCA-WFF depressing the expression of P-selectin and GPIIb/IIIa.

The minimal effective dose of ICCA-WFF to slow tumor growth is $0.5 \mu \mathrm{mol} / \mathrm{kg} / \mathrm{day}$, and the minimal effective dose of ICCA-WFF to inhibit the arterial thrombosis and the venous thrombosis is $0.5 \mu \mathrm{mol} / \mathrm{kg}$. On the other hand, however, Trp-Phe-Phe modification increases the inhibition of ICCA to tumor growth and arterial thrombosis, but does not increase the inhibition of ICCA to venous thrombosis. In addition, the in vivo activities of ICCAWFF inhibiting the expression of P-selectin and GPIIb/IIIa are significantly higher than those of ICCA. FT-ICR-MS spectrum analysis ensures that after oral administration ICCA-WFF selectively distributes to tumor tissue and arterial thrombus, i.e. exhibits the so-called tumor and arterial thrombus targeting actions. These targeting actions should be responsible for the superiority of ICCA-WFF over ICCA in anti-tumor action, anti-arterial thrombotic action and down-regulation of P-selectin and GPIIb/IIIa.

The minimal effective dose of ICCA-WFF to inhibit the arterial thrombosis and the venous thrombosis is 0.5 $\mu \mathrm{mol} / \mathrm{kg}$, both arterial thrombosis and venous thrombosis are the multiple complications of malignant tumor patients, and these emphasize that as an anti-thrombotic agent ICCA-WFF is of clinical importance. This importance is further supported by ICCA-WFF has no bleeding risk, no effect on the coagulation function and no liver or kidney toxicity.

\section{Conclusions}

Coupling 1-(4-isopropylphenyl)- $\beta$-carboline-3-carboxylic acid (ICCA) and Trp-Phe-Phe smoothly provides 1-(4-isopropylphenyl)- $\beta$-carboline-3-carbonyl-Trp-Phe-Phe (ICCAWFF). The molecular assembly leads ICCA-WFF been able to form nano-particles capable of safe delivery in the blood circulation, adhering on the surfaces of platelets, targeting tumor tissue and thrombus as well as releasing antitumor and anti-thrombotic pharmacophores wherein. ICCAWFF has no bleeding risk, no effect on the coagulation function and no liver or kidney toxicity. ICCA-WFF is a promising nano-medicine.

\section{Acknowledgments}

The authors thank the Special Project of China (2018 ZX097201003), NSFC (81673303 and 81703332), KZ201 610025029, BNSF (7172028), 2016000020124G096, and $2017000020124 \mathrm{G} 264$ for financial support.

\section{Disclosure}

The authors report no conflicts of interest in this work.

\section{References}

1. Rui L, Peng C, Zhang X, et al. Roles of Arf6 in cancer cell invasion, metastasis and proliferation. Life Sci. 2017;182:80-84. doi:10.1016/j. lfs.2017.06.008

2. Chatterjee A, Rodger EJ, Eccles MR. Epigenetic drivers of tumourigenesis and cancer metastasis. Semin Cancer Biol. 2018;51:149-159. doi:10.1016/j.semcancer.2017.08.004

3. Jansena S, Gosens R, Schmidt M. Paving the Rho in cancer metastasis: rho GTPases and beyond. Pharmacol Ther. 2018;183:1-21. doi:10.1016/j.pharmthera.2017.09.002

4. Ishikane S, Takahashi-Yanaga F. The role of angiotensin II in cancer metastasis: potential of renin-angiotensin system blockade as a treatment for cancer metastasis. Biochem Pharmacol. 2018;151:96-103. doi:10.1016/j.bcp.2018.03.008

5. Moretti A, Ferrari F, Villa RF. Pharmacological therapy of acute ischaemic stroke: achievements and problems. Pharmacol Ther. 2015;153:79-89. doi:10.1016/j.pharmthera.2015.06.004

6. Granger DN, Kvietys PR. Reperfusion therapy-What's with the obstructed, leaky and broken capillaries. Pathophysiology. 2017;24:213-228. doi:10.1016/j.pathophys.2017.09.003

7. Bonechi C, Lamponi S, Donati A, et al. Effect of resveratrol on platelet aggregation by fibrinogen protection. BiophysicalChemostry. 2017;222:41-48.

8. Van WJ, Augustine TN. Ultrastructural investigation of the time-dependent relationship between breast cancer cells and thrombosis induction. Micron. 2016;90:59-63. doi:10.1016/j.micron.2016.08.006

9. Castaman G. Risk of thrombosis in cancer and the role of supportive care (trans-fusion, catheters, and growth factors). Thromb Res. 2016;140S1:S89-S92. doi:10.1016/S0049-3848(16)30105-0

10. Jin S, Sun Z, Li X, et al. May-Thurner syndrome and the risk of pulmonary embolism in patients with acute deep venous thrombosis. J Vasc Surg Venous Lymphat Disord. 2018;6(4):433440. doi:10.1016/j.jvsv.2018.01.007 
11. Faustino EVS, Shabanova V, Pinto MG, et al. Epidemiology of lower extremity deep venous thrombosis in critically $\mathrm{Ill}$ adolescents. J Pediatr. 2018;201:176-183.e2. doi:10.1016/j.jpeds.2018.05.006

12. Liu K, Wang $H$, Cui $Y$, et al. Handgrip exercise reduces peripherally-inserted central catheter-related $\mathrm{T}$ venous thrombosis in patients with solid cancers: a randomized controlled trial. Int J Nurs Stud. 2018;86:99-106. doi:10.1016/j.ijnurstu.2018.06.004

13. Hmoud B, Singaly AK, Kamathz PS. Mesenteric venous thrombosis. $J$ Clin Exp Hepatol. 2014;4:257-263. doi:10.1016/j.jceh.2014.03.052

14. Karsy M, Harmer JR, Guan J, et al. Outcomes in adults with cerebral venous sinus thrombosis: a retrospective cohort study. J Clin Neurosci. 2018;53:34-40. doi:10.1016/j.jocn.2018.03.004

15. Gazioglu S, Eyuboglu I, Yildirim A, et al. Cerebral venous sinus thrombosis: clinical features, long-term outcome and recanalization. $J$ Clin Neurosci. 2017;45:248-251. doi:10.1016/j.jocn.2017.07.028

16. Xu YM, Liu J, Qiu XW, et al. Characteristics and management of free flap compromise following internal jugular venous thrombosis. J Oral Maxillofac Surg. 2018;76(11):2437-2442. doi:10.1016/j. joms.2018.05.006

17. Aschermann M. Prevention of arterial and venous thrombosis in cancer patients. Cor Vasa. 2013;55:e196-e200. doi:10.1016/j.crvasa. 2013.03.001

18. Javid M, Magee TR, Galland RB. Arterial thrombosis associated with malignant disease. Eur J Vasc Endovasc Surg. 2008;35:84-87. doi:1 0.1016/j.ejvs.2007.08.014

19. Valéra M-C, Noirrit-Esclassan E, Dupuis M, et al. Effect of estetrol, a selective nuclear estrogen receptor modulator, in mouse models of arterial and venous thrombosis. Mol Cell Endocrinol. 2018;477:132-139. doi:10.1016/j.mce.2018.06.010

20. Nicolajsen CW, Dickenson MH, Budtz-Lilly J, Eldrup N. Frequency of cancer in patients operated on for acute peripheral arterial thrombosis and the impact on prognosis. J Vasc Surg. 2015;62:1598-1606. doi:10.1016/j.jvs.2015.06.223

21. Aronson D, Brenner B. Arterial thrombosis and cancer. Thromb Res. 2018;164:S23-S28. doi:10.1016/j.thromres.2018.01.003
22. Chen H, Peng S, Zhao M, et al. Design and development of ICCA as a dual inhibitor of GPIIb/IIIa and P-selectin receptors. Drug Des Devel Ther. 2018;12:2097-2110. doi:10.2147/DDDT.S169238

23. Zhao M, Bi L, Wang W, et al. Synthesis and cytotoxic activities of $\beta$ carboline amino acid ester conjugates. Bioorg Med Chem. 2006;14 (20):6998-7010. doi:10.1016/j.bmc.2006.06.021

24. Wu J, Li C, Zhao M, et al. A class of novel carbolineintercalators: their synthesis, in vitro anti-proliferation, in vivo anti-tumor action, and 3D QSAR analysis. Bioorg Med Chem. 2010;18(17):6220-6229. doi:10.1016/j.bmc.2010.07.043

25. Hu X, Zhao M, Wang Y, et al. Tetrahydro- $\beta$-carboline-3-carboxylthymopentin: a nano-conjugate for releasing pharmacophores to treat tumor and complications. J Mater Chem B. 2016;4(8):1384-1397. doi:10.1039/C5TB01930C

26. Zhu H, Wang Y, Song C, et al. Docking of THPDTPI: to explore P-selectin as a common target of anti-tumor, anti-thrombotic and anti-inflammatory agent. Oncotarget. 2018;9:268-281. doi:10.186 32/oncotarget.v9i1

27. Jin S, Wang Y, Zhu H, et al. Nanosized aspirin-Arg-Gly-Asp-Val: delivery of aspirin to thrombus by the target carrier Arg-Gly-Asp-Val tetrapeptide. ACS Nano. 2013;7(9):7664-7673. doi:10.1021/nn402171v

28. Gadi D, Bnouham M, Aziz M, et al. Parsley extract inhibits in vitro and ex vivo platelet aggregation and prolongs bleeding time in rats J Ethnopharmacol. 2009;125(1):170-174. doi:10.1016/j.jep.2009.05.014

29. Jianhui W, Peng S, Zhao M, et al. BCESA: a nano-scaled intercalator capable of targeting tumor tissue and releasing anti- tumoral $\beta$-carboline -3-carboxylic acid. Int $J$ Nanomedicine. 2019;14:3027-3041. doi:10.2147/IJN.S187600

30. Wang X, Wang Y, Wu J, et al. Docking based design of diastereoisomeric MTCA as GPIIb/IIIa receptor inhibitor. Bioorg Med Chem Lett. 2017;27(23):5114-5118. doi:10.1016/j.bmcl.2017.10.068

31. Wang Y, Peng S, Zhao M, et al. Dimethyl 2,2'-[2,2'-(ethane-1,1-diyl)bis(1Hindole-3,2-diyl)]-diacetate: a small molecule capable of nano-scale assembly, inhibiting venous thrombosis and inducing no bleeding side effect. Int J Nanomedicine. 2018;13:7835-7844. doi:10.2147/IJN.S178683
International Journal of Nanomedicine

\section{Publish your work in this journal}

The International Journal of Nanomedicine is an international, peerreviewed journal focusing on the application of nanotechnology in diagnostics, therapeutics, and drug delivery systems throughout the biomedical field. This journal is indexed on PubMed Central, MedLine, CAS, SciSearch ${ }^{\mathbb{R}}$, Current Contents ${ }^{\mathbb{B}} /$ Clinical Medicine,
Journal Citation Reports/Science Edition, EMBase, Scopus and the Elsevier Bibliographic databases. The manuscript management system is completely online and includes a very quick and fair peer-review system, which is all easy to use. Visit http://www.dovepress.com/ testimonials.php to read real quotes from published authors. 